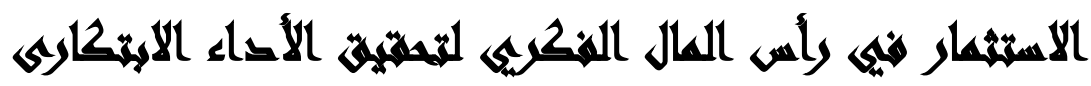

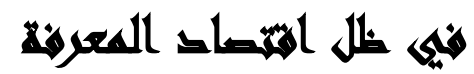

\section{$\left[r^{r}\right]$}

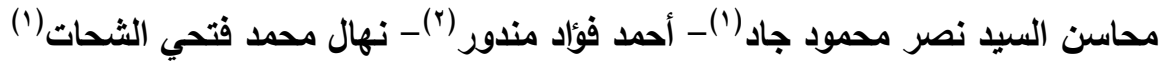

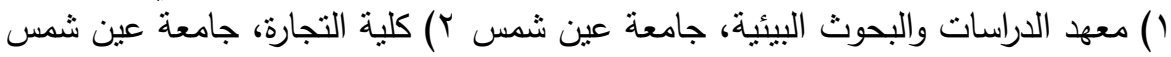

\section{المستخليس}

يهدف هذا البحث للأثارة عن دور أستثمار رأس المال الفكري كدخل للنمو والتتمية

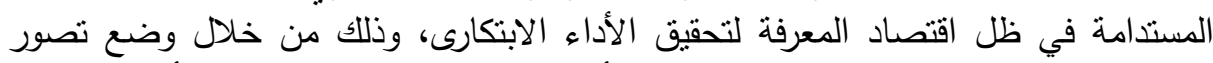

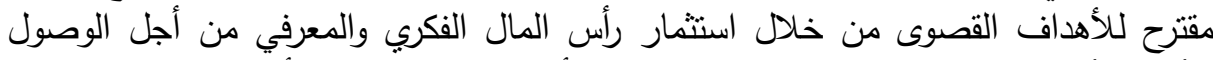

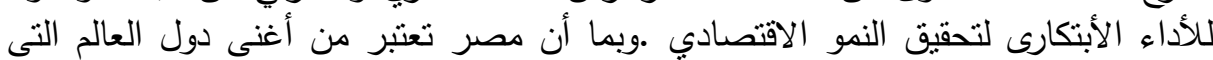

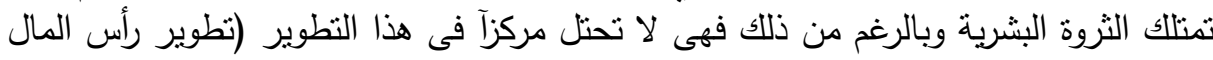

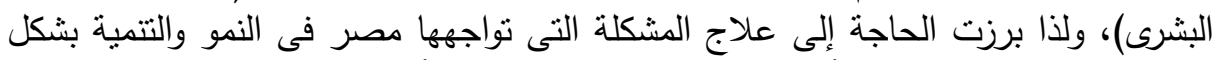

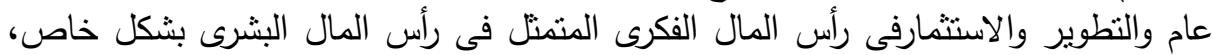

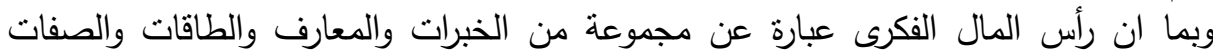

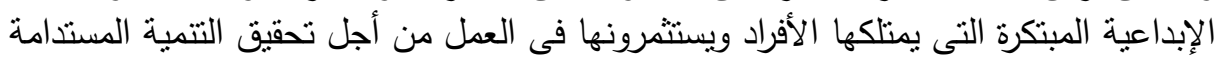

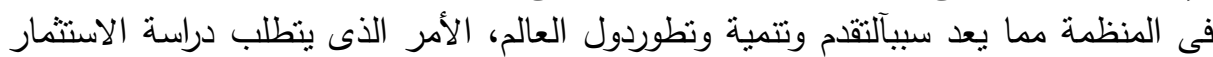

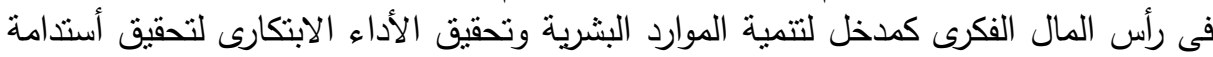

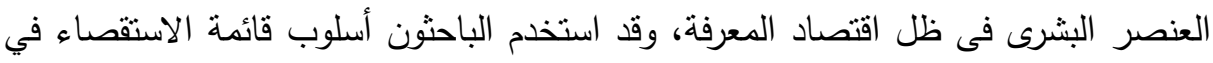

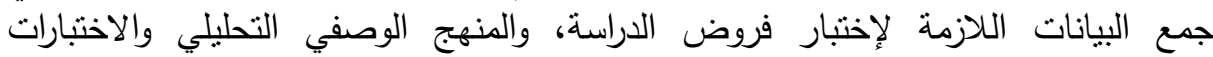

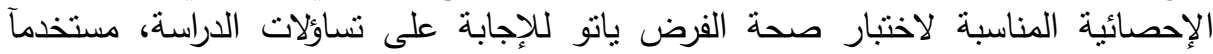

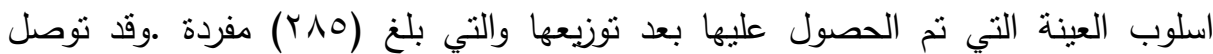

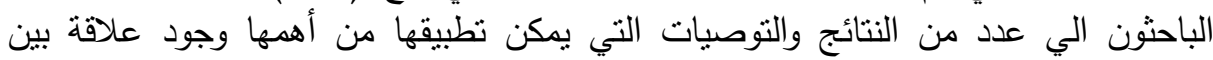

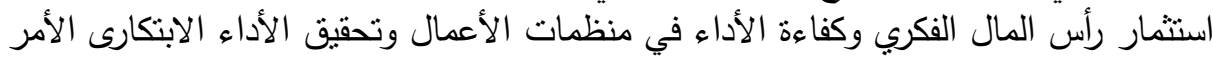

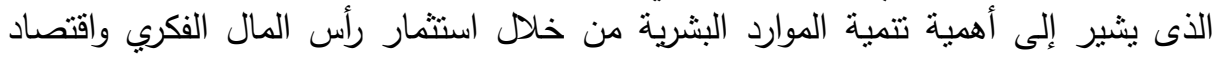

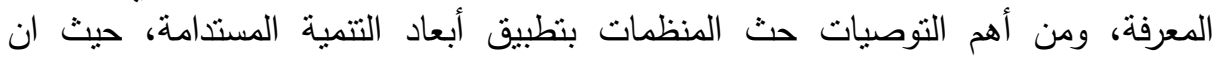

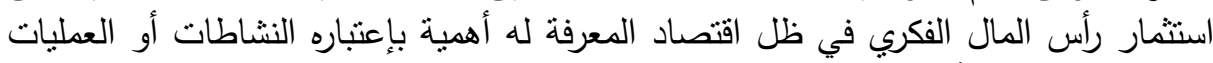

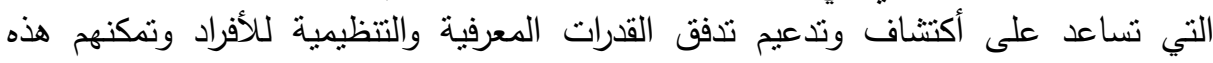

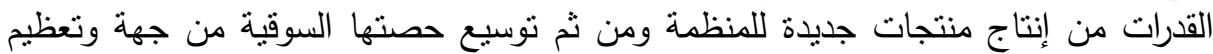

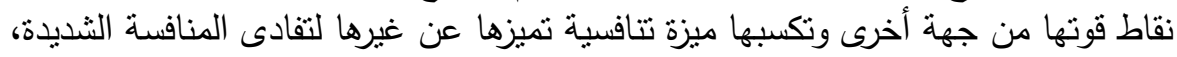

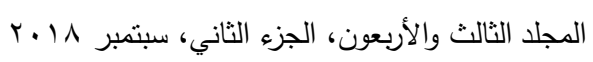


كما يجب ان تبني المنظمة إستراتيجية واضحة ومحددة لإدارة المواهب داخل المنظمات

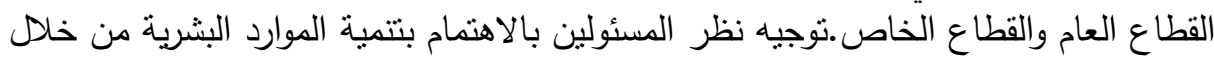

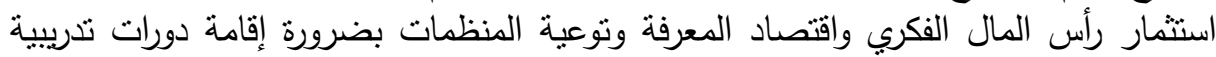
للعاملين بمختلف المستويات الادارية حول رأس المال الفكري واقتصاد المعتية المعرفة وكيفية

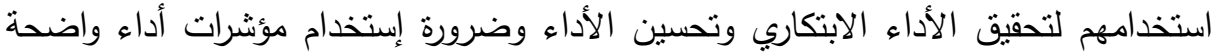

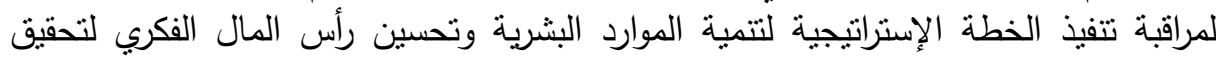
الأداء الابتكارى فيظل اقتصاد المعرفة.

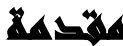

أن تقرير التتمية البشرية هو تقرير سنوى يصدر عن برنامج الأمم المتحدة الإنمائى

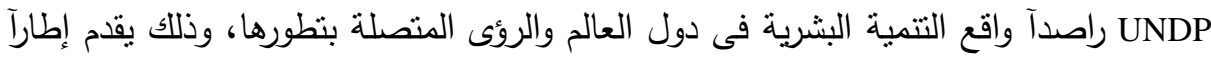
لكساعدة أصحاب القرار من الحكومات والأفراد على تطبيق هذه الرؤى على سياسة التتمية وقد

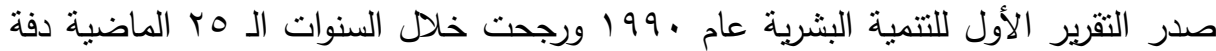
النمو الاقتصادى لكونه مؤشرآ مهمآ على التتمية البشرية، إلا أن تقرير عام 10 ب أعاد العاد

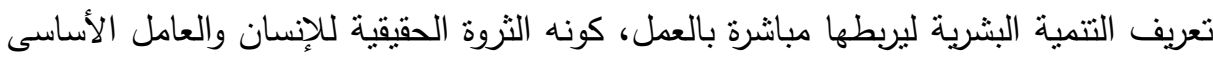
الذى يساهم فى نطور الاقتصاد وتحُدث التقرير عن الأعمال النطوعية والإبداعية وأعمال الرعاية بالإضافة إلى العمل المدفوع الأجر (الوظيفة)، وببساطة فإن المفهوم الحاكم للتتمية هو الهو

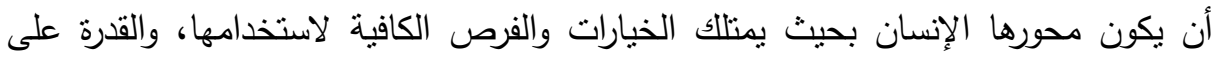
التأثير فى حياته وعليه يُعد النمو الاقتصادى وسيلة لاغاية وقيمته تتحدد بمدى تحسين جودة

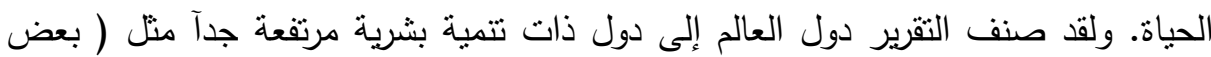

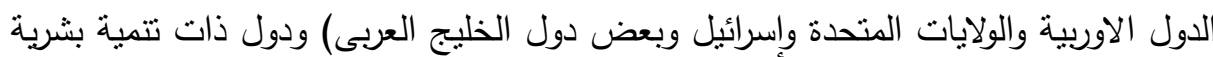
مرتفعة مثل ( روسيا وبعض دول الخليج ) ودول ذات تتمية متوسطة مثل ( معظم الدول

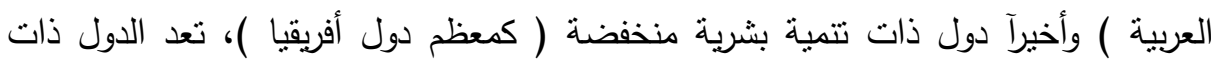
التتمية المرتفعة جدآ تلك التى يكون مؤشرها يتراوح بين (^،، - ( ) وعددها هذا العام 9؟

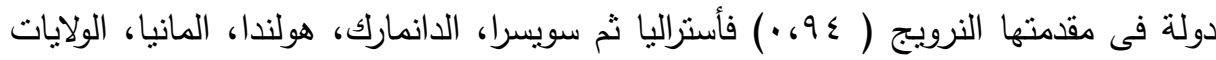
المتحدة، كندا، نيوزيلندا، وسنغافوره. وعربياً جاءت قطر فى المرنبة بس عالمياً وفى طليعة 
الدول العربية وتلتها السعودية فى المرتبة وب فالامارات والبحرين والكويت وفى عداد الدول

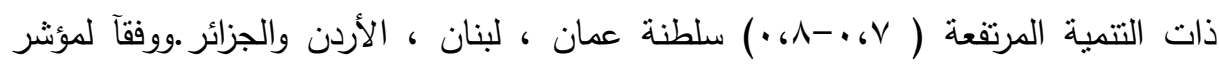

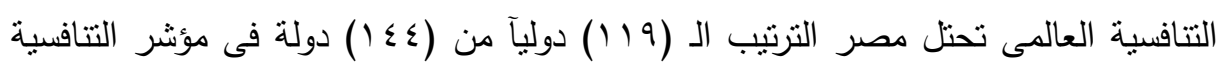

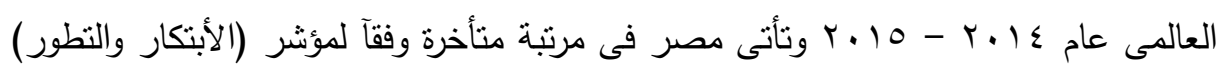

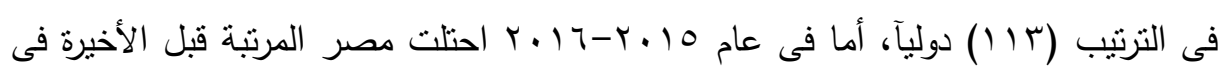

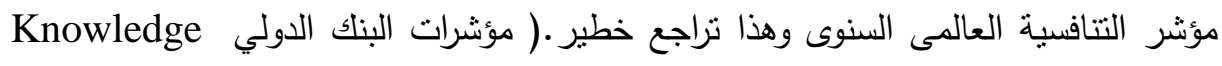
. (Assessment Methodology - KAM,2017

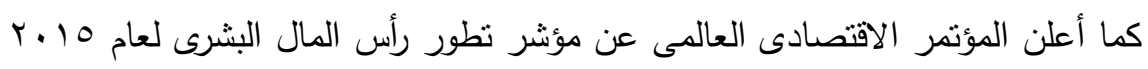

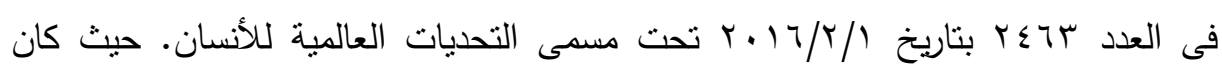

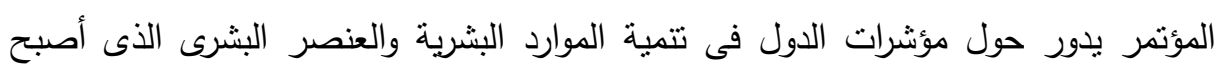

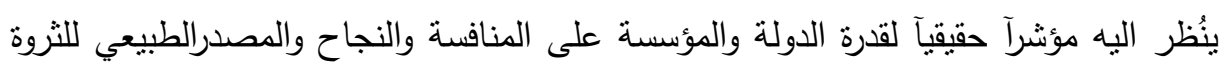

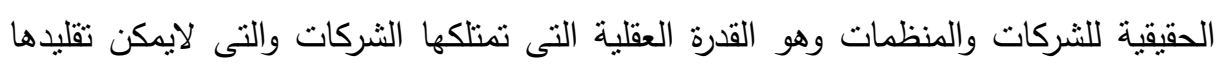

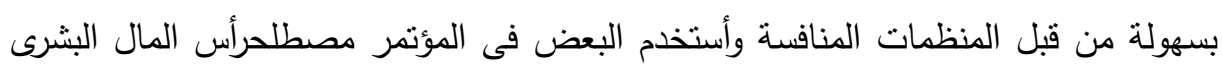

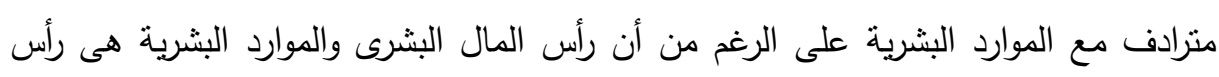

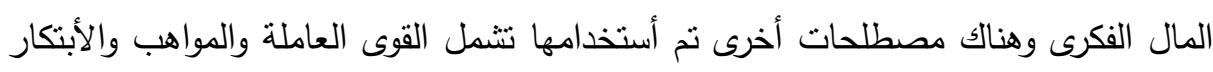

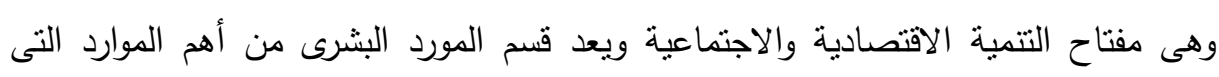
تعتمد عليها خطط التتمية فى جميع القطاعات كما ترسم إدارات الموارد البشرية خطط الانتاج والنسويق والصيانة والثراء ويجب على تللك الإدارات التخطيط والتدريب الدائم لمواردها لتحقيق

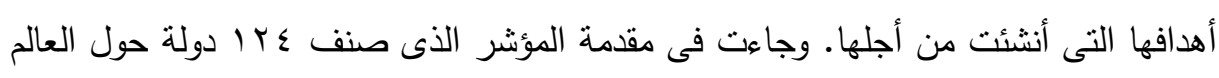

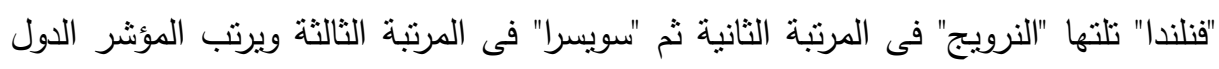

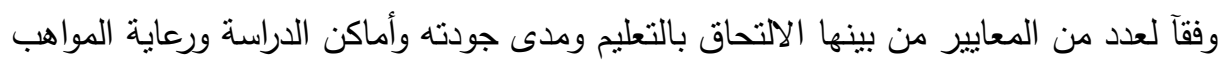

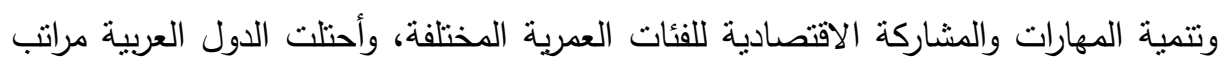

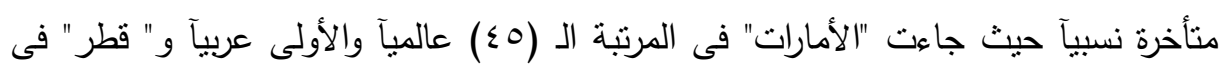

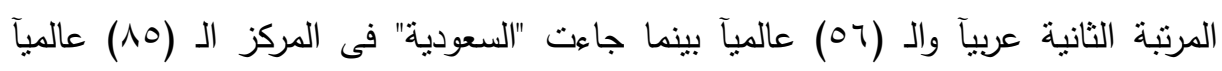

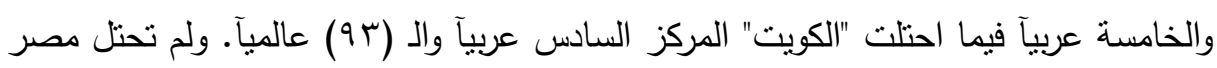

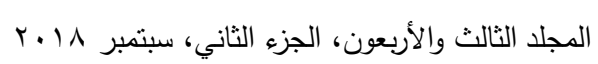


أى مركز فى هذا التطوير ولذلك برزت الحاجه إلى إلى علاج المشكلة التى تواجهها مصر فى النمو والتتمية بشكل عام والنطوير والاستثمارفى رأس المال الفكرى المتمتل فى رأس المال

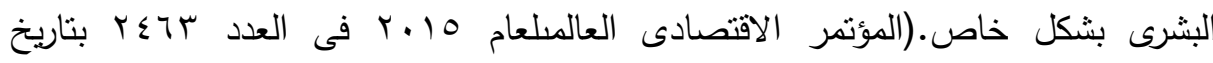
$\cdot(r \cdot 1 T / r /)$

\section{And ILAR}

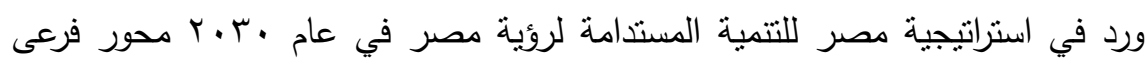

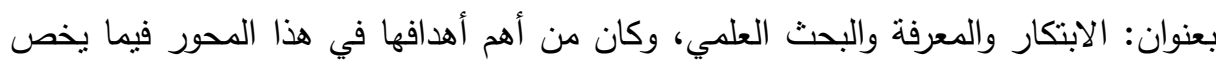

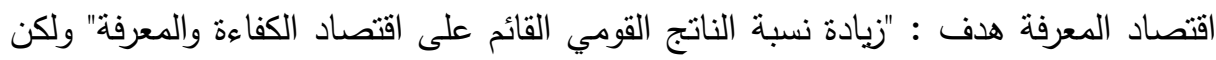
لم يتم وضع مؤشرات لكيفية تحقيق هذا العنصر أو كيفية قياسه، كما هدفت استراتيجية قطاع

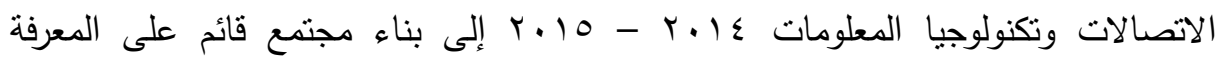

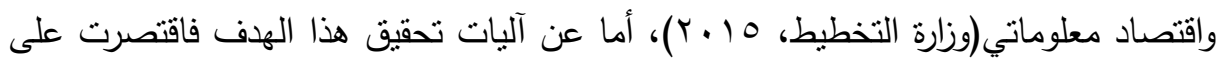
توفير بنية أساسية فعالة لتطوير تكنولوجيا المعلومات والاتصالات تقوم على استخدام الإنترنت

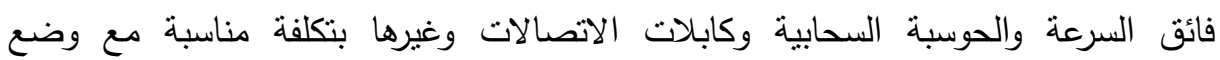

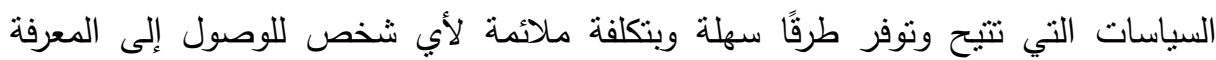

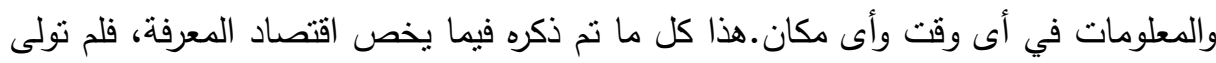
تلك الاستراتيجيات أى اهتمام بجوهر اقتصاد المعرفة القائم على الاستثمار فى رأس المال الفكرى وتتمية الموارد البشرية التى تساهم فيإنتاج وتوزيع واستخدام المعرفة والمعلومات لتحقيق التهري

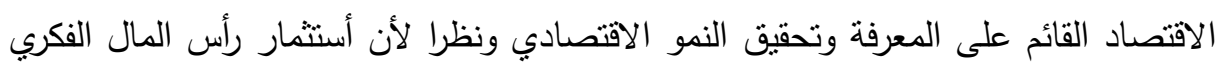
من خلال اقتصاد المعرفة لم يأخذ حقه، من هنا ثبرز مشكلة البحث لأستثمار رأس المال

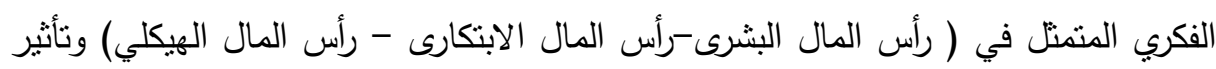
كل منهما على تتمية الموارد البشرية في ظل اقتصاد المعرفة المتمنلة في ( التقوق التتافسى التئي المستدام - القدرة التتافسية المستدامة - الابتكار - البنية التحتية المعلوماتية - التعلم المستمر لهرئه والنمو المستدام - التتمية البشرية المستدامة)لتحقيق الأداء الابتكارى المتمنل فى (إدارة المواهب - التجديد والإبتكار - التميز - التدريب والتعلم - تحسين الأداء فى المنظمة). 560

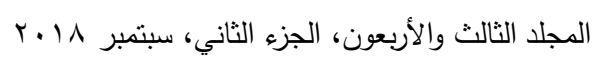


وباستعراض الدراسات السابقة ومنها دراسة (مها عادل الزيادى، 10 • ب)، ودراسة (ممدوح عبد

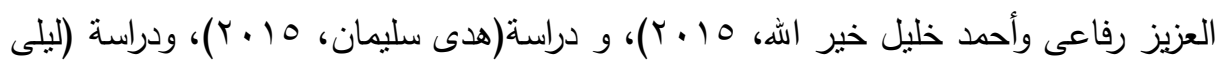

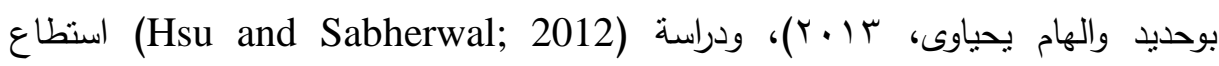

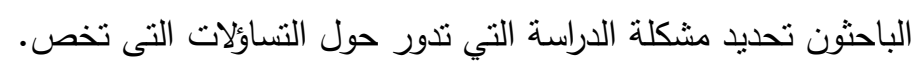

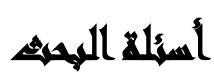

• ما دور الأستثمار في رأس المال الفكري على تتمية الموارد البشرية في ظل اقتصاد المعرفة؟

• ما دور الأستثمار في رأس المال الفكري فى تتمية الموارد البشرية لتحقيق الأداء

$$
\text { الابتكارى؟ }
$$

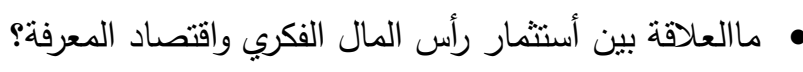

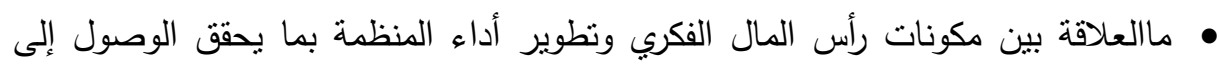

$$
\text { تحقيق النمو الاقتصادي؟ }
$$

• ما أثز رأس المال الفكري بمتغيراته على كفاءة الأداء في منظمات الأعمال؟

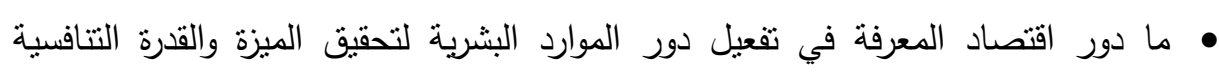

للمنظمة؟ مان

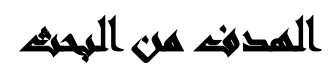

يهدف هذا البحث الكثف عن دور أستثمار رأس المال الفكري كمدخل للنمو والتتمية

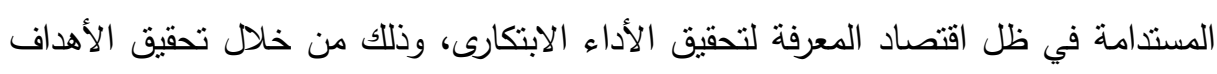

التالية: • التعرف على أستثمار رأس المال الفكري كمدخل لتتمية الموارد البشرية وأستدامة العنصر

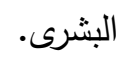

• تحديد أثر رأس المال الفكري بمتغيراته على كفاءة الأداء في منظمات الأعمال. • تحديد أثز التطور الذي يحدث في الأداء من خلال اقتصاد المعرفة وتتمية العقول

$$
\text { البثرية. }
$$

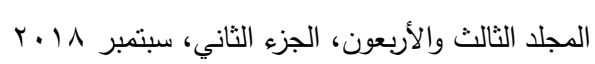


التعرف على مصطلح جديد ينتج عن استثمار رأس المال الفكري وتطوير الأداء وهو

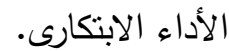

• وضع تصور مقترح للأهداف القصوى من خلاد استثمار رأس المال الفكري والمعرفي من أجل الوصل للأداء الابتكارى لتحقيق النمو الاقتصادي.

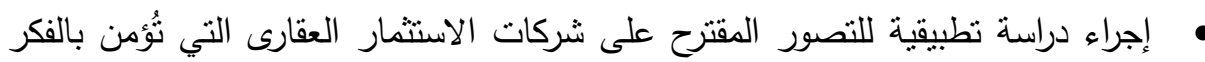
الأبنكارى والنظر خارج الصندوق.

\section{أمهيد المهيم}

تكمن أهمية البحث في دراسة وتحليل أحد المواضيع الهامة والحديثة المطروحة خصوصا انها نساهم فتحقيق التتمية المستدامة وتحسين الاداء الاقتصادى والبيئى، فالمؤسسة الاقتصادية باعتبارها المصدر الرئيسي للثروة والأداة الفاعلة في اقتصاد أي دولة معنية بتطبيق أبعاد التتميةالمستدامة، حيث ان أستثمار رأس المال الفكري في ظل اقتصاد المعرفة

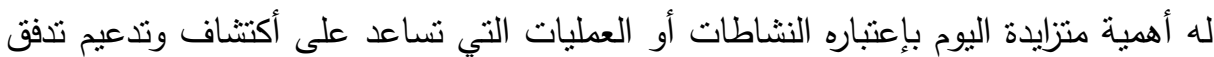
القدرات المعرفية والتتظيمية للأفراد وتمكنه هذه القدرات من إنتاج منتجات جديدة للمنظمة ومن ثم توسيع حصتها السوقية من جهة وتعظيم نقاط قوتها من جهة أخرى وتكسبها ميزة تتافسية تميزها عن غيرها لتفادى المنافسة الثديدة فى ظل اقتصاد المعرفة وتكمن أهمية

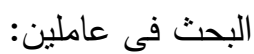
1- كؤن عناصر رأس المال الفكرى تعتبر مؤشرات لقياس مدى تطور الفكر الإدارى بمنظمات

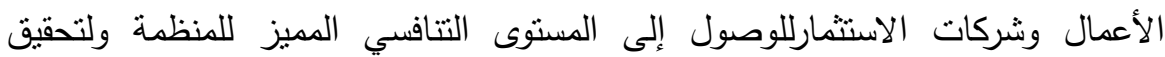
الأهداف القصوى التي تسعى لتحقيقها المنظمة من حيث الوصول إلى الأداء الابتكارى

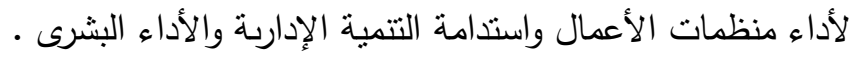

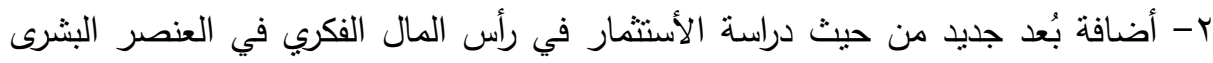

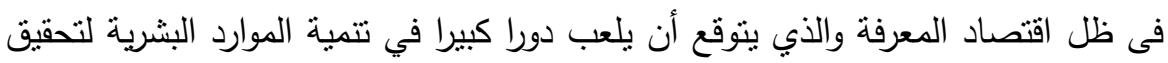

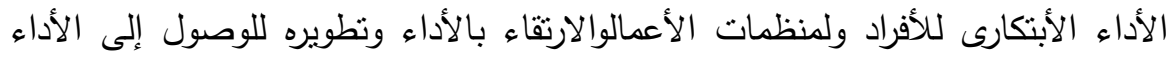
المميز الذي يُمكن المنظمة للوصول إلى الميزة التنافسية. 
كما تبرز أهمية هذا البحث في التعرف على إمكانية الإستفادة من المواهب البشرية

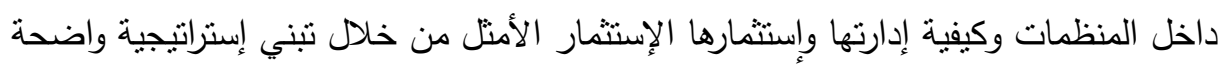

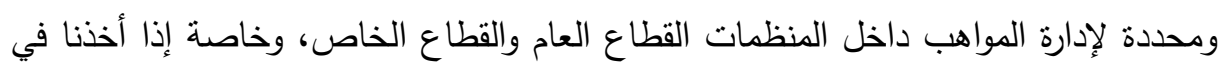
الحسبان الطبيعة المميزة لهذه المواهب مما تعطي الفرصة الحقيقية للمنظمات من زيادة

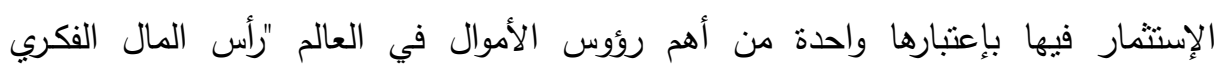

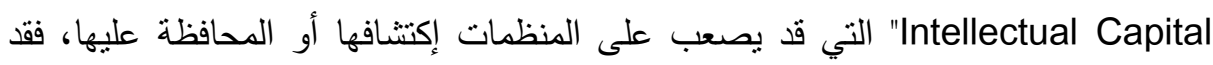
تتقل المنظمة من حالٍ إلى حالٍ أفضل بين منافسيها.

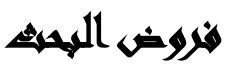

$$
\text { تتمثل فروض البحث في: }
$$

• توجد علاقة جوهرية ذات دلالة إحصائيه بين استثمار رأس المال الفكري وتتمية الموارد

$$
\text { البشرية. }
$$

• توجد علاقة جوهرية ذات دلالة إحصائيه بين استثمار رأس المال الفكري واقتصاد المعرفة.

• • • • • ثدجد علاقة جوهرية ذات دلالة إحصائيه بين تتمية الموارد البشريةواقتصاد المعرفة.

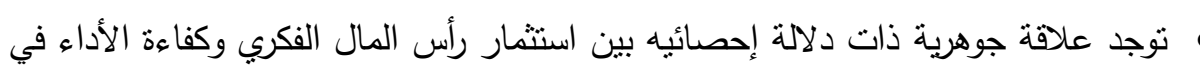
منظمات الأعمال وتحقيق الأداء الابتكارى.

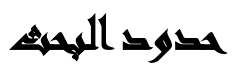

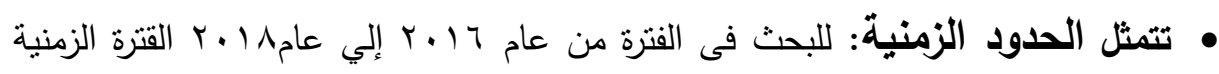
التى اصبح من الضروري تحليل كيف كانت بيئة العمل الداخلية بشركات الاستثمار العقارى ومحدداتها وما تركته من أثر على البعد البيئي والاقتصادي وتحسين الأداء لتحقيق لـئه النمو والأستدامة. • كما تمثل الحدود المكانية: تحديد مكان الدراسة وقد تم إختبار شركات الاستثمار العقارى فى القاهرة عامة ومجموعة عامر جروب خاصة.

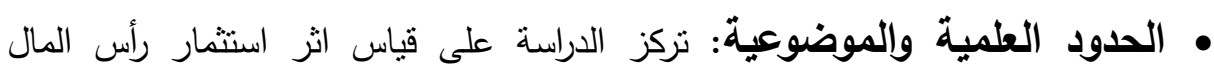
الفكري لتحقيق الأداء الابتكارى في ظل اقتصاد المعرفة.

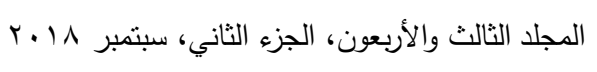




\section{التراسايت السائية}

دراسة (مها عادل الزيادى 1 ب ب): نموذج لأثر رأس المال الفكري وجودة الحياة

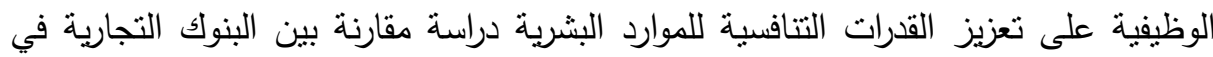

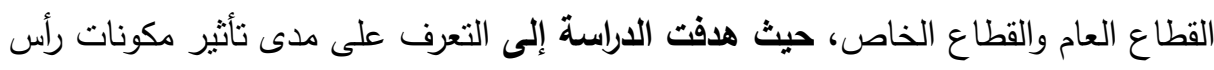

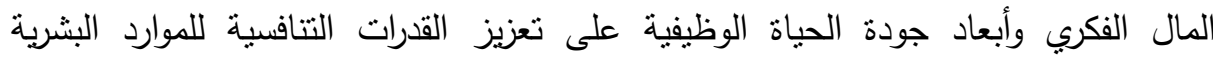

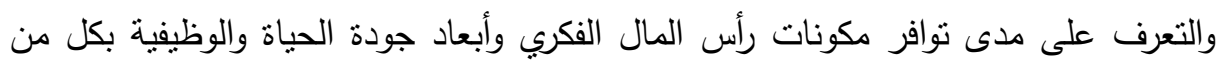
البنوك التجارية في القطاع العام والقطاع الخاص وتوصلت النتائج إلى تباين أستجابة العاملين في ننائج الوصف الأحصائى حسب نوع القطاع والمستويات الإدارية والوظائف النمطية لكل

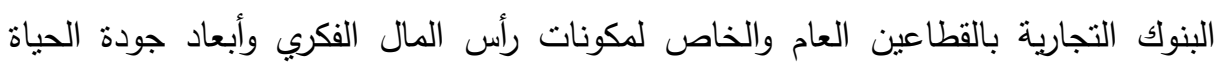
الوظيفية وأبعاد تعزيز القدرات التنافسية للموارد البشرية.

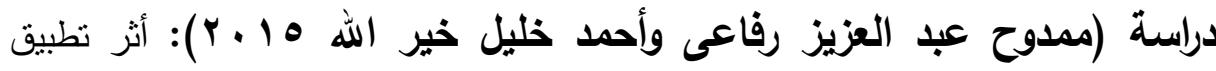

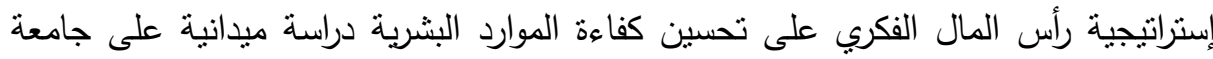
عين شمس، وهدفت الداسة إلى التعرف على مدى دعم الإدارة العليا بالجامعات العكومية العادية

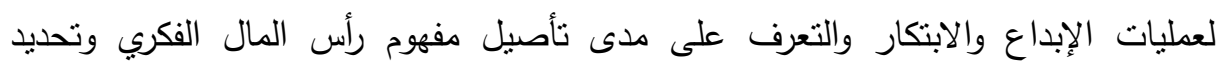

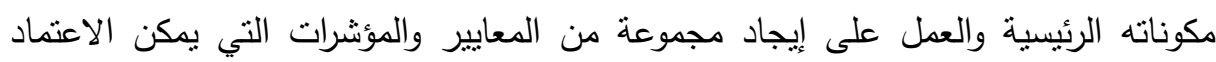

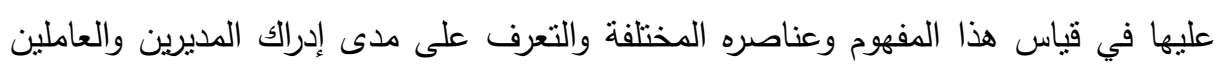

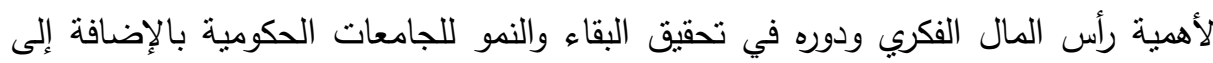

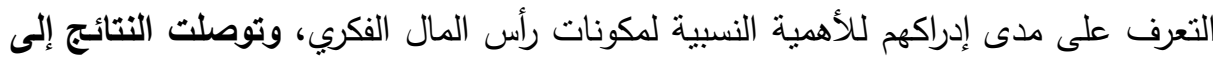

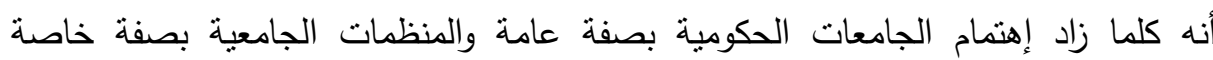

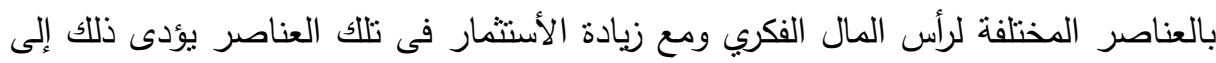

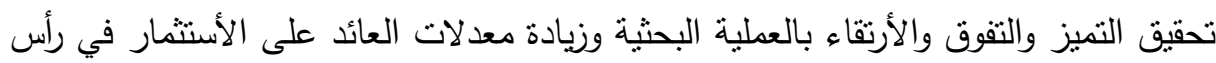
المال البشرى لدى تلك المنظمات مما ينعكس إيجابيا على تحسين مستوى الأداء الكلى الكي للجامعات الحكومية المصرية والتى تمثلها جامعة عين شمس محل الدراسة. 
دراسة( هلى سليمان، ه 1 • †): أثرالرعاية المهنية على تتمية الموارد البشرية لتحقيق

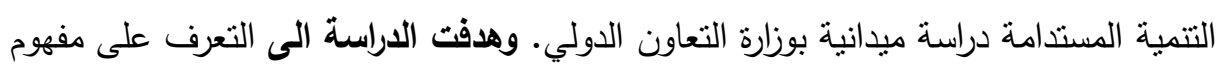

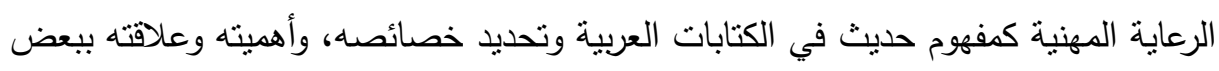

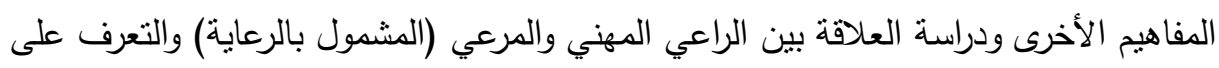

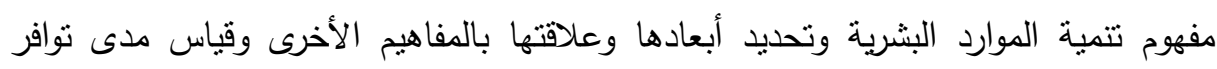

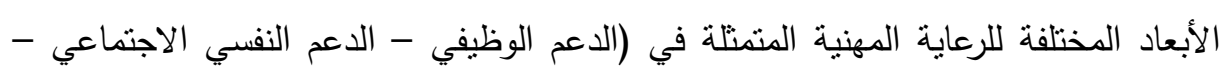

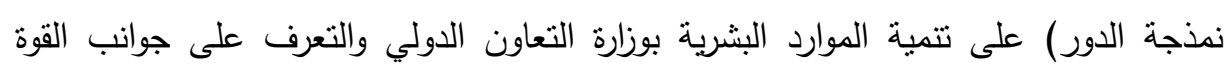

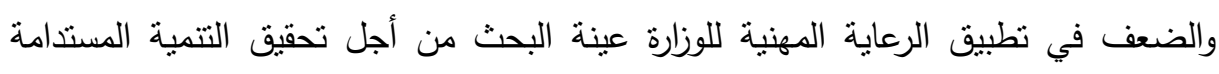

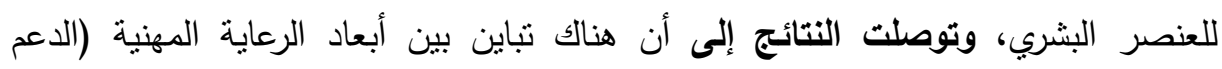

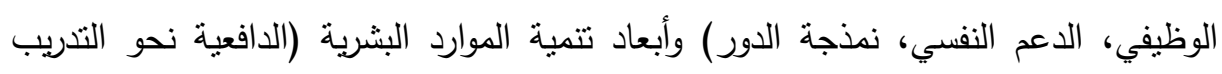

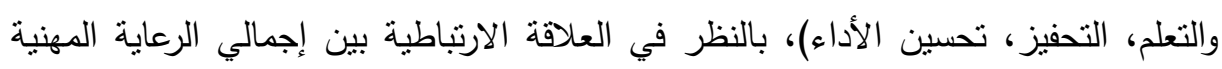

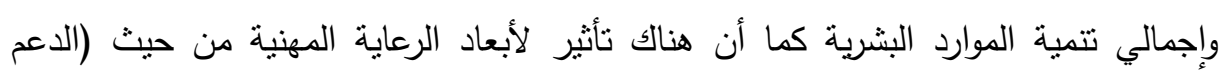

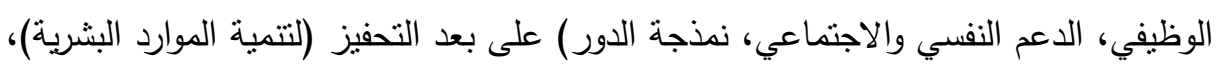

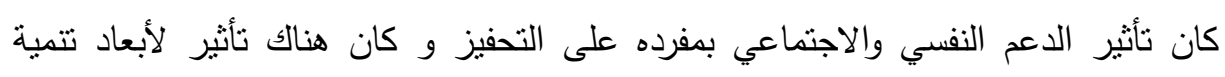

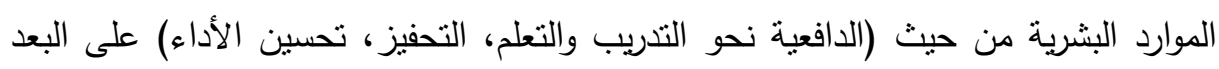
البشري والبيئي (التتمية المستدامة).

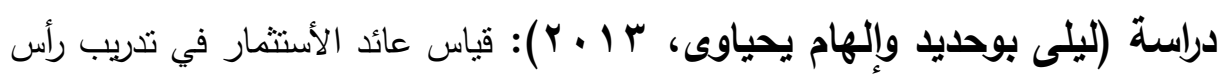
المال الفكري في ظل اقتصاد المعرفة، وهدفت الدراسة إلى التعرف على كيفية قياس الأستثمار في تدريب رأس المال البشرى في ظل اقتصاد المعرفة من خلال التطرق إلى حالة

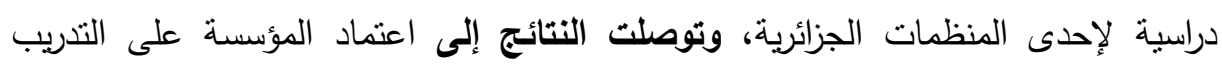

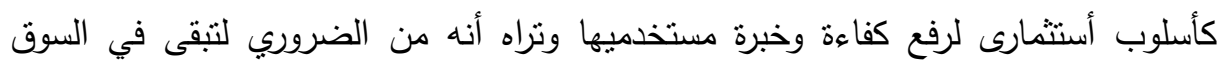
والتقدم أكثر نحو الأحسن وتحقيق النتائج الإيجابية بعد التدريب مثل تخفيض الوقت وتئن وتحسين

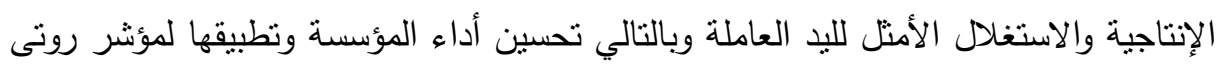

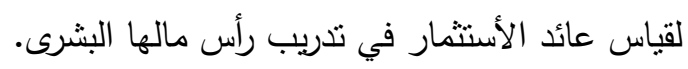




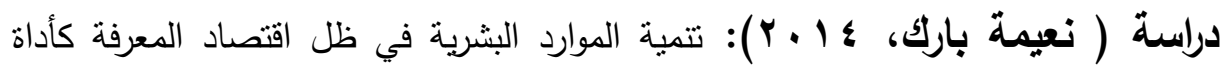

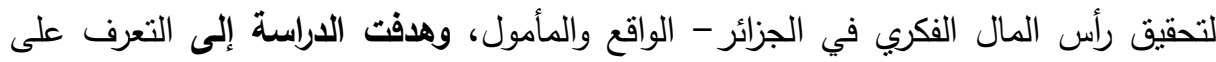

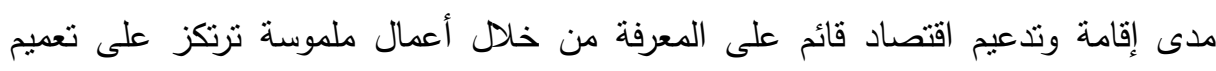
استعمالات تكنولوجيا الأعلام والاتصال وجعلها في قلب عملية عصرنة الإدارة وجزءا لا يتجزأ

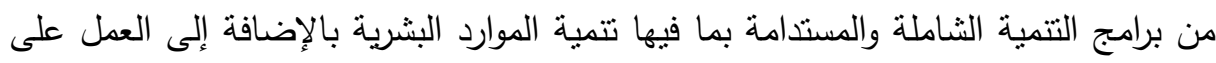

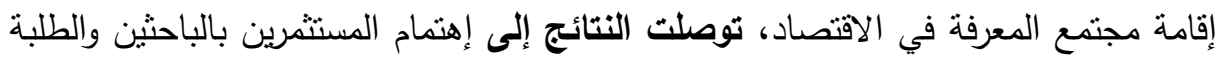
المتفوقين فى كل التخصصات وتمكينهم على الاستفادة من برامج تدربيية بالخارج لزيادة إهاد

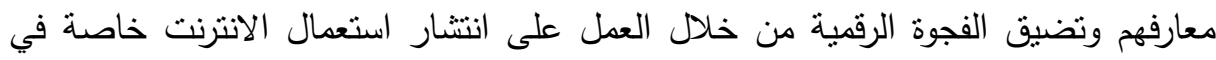

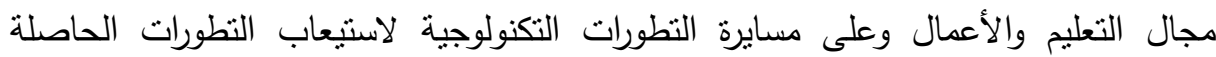
خاصة فى مجال تكنولوجيا المعلومات و الاتصالات. Science park Schiavone,et,al.2014) Sراسة (ستقصاء أثز موقع مجمع العلوم على مستوى أداء رأس المال الفكري بالمؤسسة، وقد أظهرت نتائج الاراسة أن مكان وجود

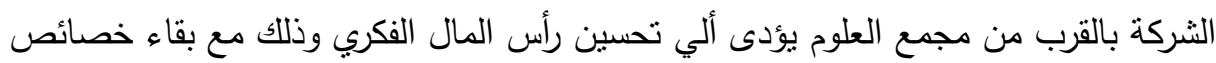
المؤسسة مثل الحجم والعمر والنفوذ عنصرا مؤثرا في التتبؤ بأداء رأس المال الفكري.

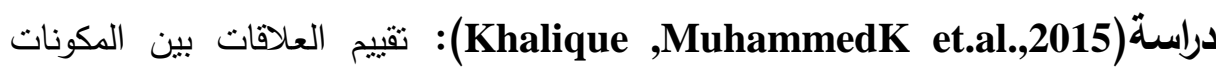
الفرعية لرأس المال الفكري والأداء التتظيمي وذللك في الثركات الصغرى والمتوسطة في قطاع الصناعات الكهربائية والالكترونية في باكستان، وقد أظهرت النتائج ملائمة عناصر ومكونات لتهردي رأس المال الفكري وذلك في درجة تأثيرها على الأداء التنظيمي وكانت النتائج معنوية، بينما المكون الوحيد وهو رأس المال البشرى لم يثبت تأثيرها ولم يكن معنويا في التأثثر على الأداء 


\section{الإطار اللنظيه}

رأس المال الفكري: هو الموهبة والمهارات والمعرفة التقنية والعلاقات، وكذلك الماكينات

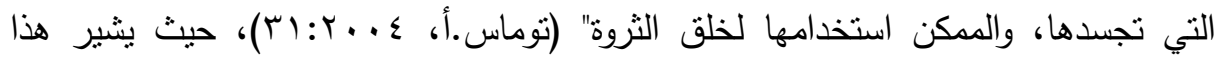
التعريف إلى أن رأس المال الفكري هو المعرفة (المهارات، الخبرات، والتعليم المتراكم في لهني

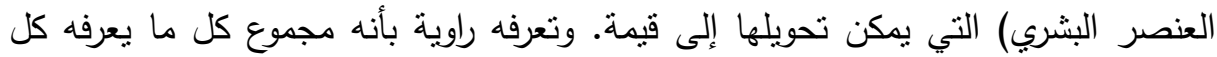

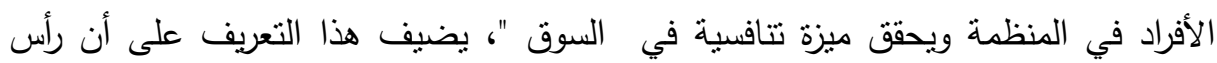
المال الفكري كمصدر لتحقيق الميزة التتافسية الني تمكن المنظمة من مواجهة المنافسة الثديدة

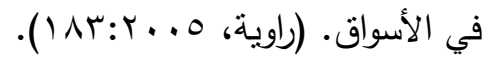
إدارة رأس المال الفكري: ظهور هذا الدفهوم مقترن مع زيادة أهمية المعرفة في انجاز الأنشطة وانتشارها الواسع، فأصبحت المنظمات تنظر إلى المنتجات المعرفية التي هي نتاج

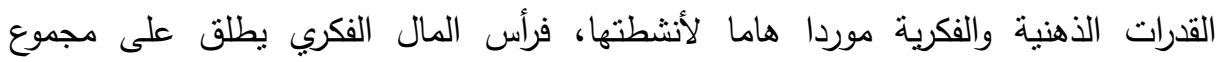

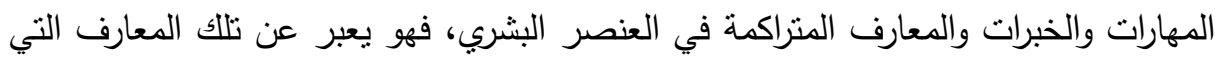

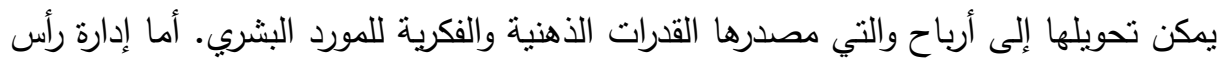
المال الفكري فنتير إلى تلك الأنشطة والجهود التي تهنم بكيفية توفير تلك القدرات والحفاظ عليها وتتميتها واستغلالها أحسن استغلال بشكل بدعم المركز التتافسي للمنظمة ويضمن بقائها

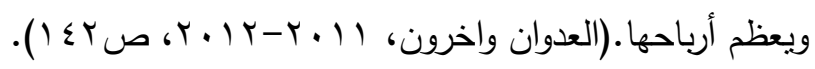

اقتصاد المعرفة: يمكن تعريف اقتصاد المعرفة بأنه هو الاقتصاد الذى تحقق فيه المعرفة

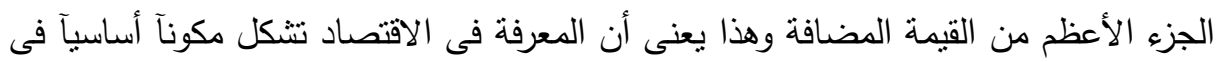
العملية الإنتاجية كما فى النسويق، وأن النمو بزداد بزيادة هذا المكون القائم على تكنولوجيا

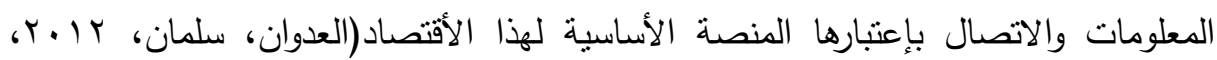
. (1) ص (1)

الآداء الابتكارى: هو أداء يهدف إلى الأستغلال الأمتل للكفاءات البشرية من خلال أستقطاب المواهب وتتميتها وتحفيزها ودمجها فى مسار تحقيق الأهداف الأستراتيجية بتوفير بيئة العمل المناسبة لتفجير قدراتهم وإمكانياتهم المحتملة والأستفادة من رصيد المعرفة الكامنة

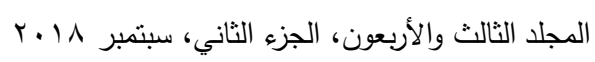


لدى تللك الكفاءات والعمل على توظيفها بما يؤدى إلى خلق القدرات البشرية الهائلة وتحقيق المبزة التنافسية والوصول إلى الصداره (مفهوم جديد لم يذكر من قبل فى علم إدارة الأعمال وهو من الاتجاهات الحديثة فى الفكر الإدارى المصدر هو الباحثة ). التنمية الإدارية: التتمية الإدارية عملية تدخل هادفة منظمة نسعى إلى جعل عمليات الإدارة وطرقها ووسائلها تتلاءم مع مرحلة التطور، وكنلك جعل عمليات الإدارة وطرقها وتقنياتها تتواءم مع الأهداف التتموية الثاملة "الإقتصادية والإجتماعية والثقافية". ويمكن تعريفها أيضا على أنها إستراتيجية تدخل شاملة تعتمد على جهد منظم يهدف إلى إحداث التغيير بغية تحسين كفاءة وفاعلية الجهات الإدارية لنطوير مقدرتها على التجدد والتطور والتلاؤم مع

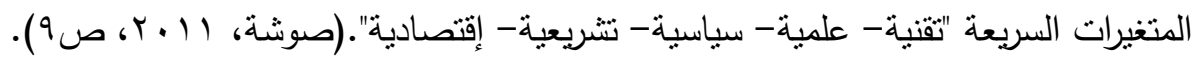
تثمية الموارد البشرية: تتشير إلى تلك الجهود والنشاطات التي تستهدف نتمية العنصر البشري في العملية الإنتاجية، إذ تتمنل في أنشطة نوفير المورد البشري ورفع قدراته وتطويرها ثم تعظيم مساهمته في تحسين أداء المنظمة وتطويره، ونشير هنا إلى الفرق الجوهري بين تتمية الموارد البشرية والتتمية البشرية في كون أن هذه الأخيرة تمنل نلك الأنشطة التي ترفع

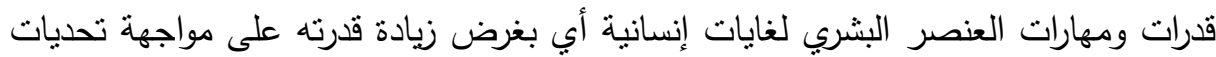
وصعوبات حياته، فهي نتظر إلى العنصر البشري كانسان وبذللك فهي تكز الجهود لتنميته لذاته، حيث ينم تقييم الجهود في إطار التتمية البشرية بمؤشرات إنسانية تدل على مدى تحسن لئن حياة ورفاهية الإنسان، على عكس تتمية الموارد البشرية التي تقوم برفع قدرات ومهارات

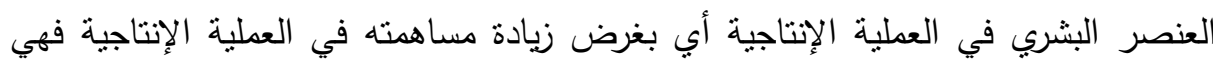
تتظر إلى العنصر البشري كمورد للعملية الإنتاجية لهذا فهي تركز على طاقاته وقدراته التي لئي

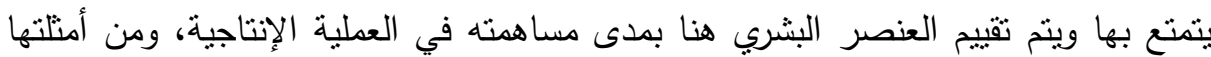

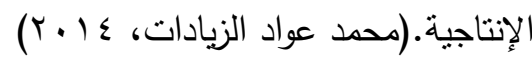

التطوير التظيمي: هو خطة طويلة المدى لتحسين أداء المنظمة في طريقة حلها للمشاكل وتجديدها وتغييرها لممارساتها الإدارية، وتعتمد هذه الخطة على مجهود تعاوني بين الإداريين

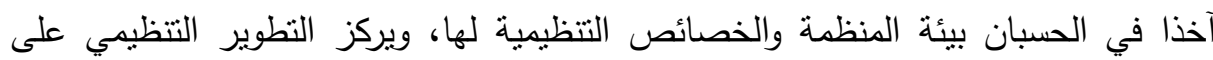
568

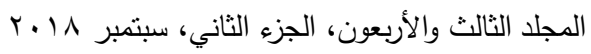


الخصائص البنيوية والتنظيمية للمنظمة، ويهدف إلى زيادة المرونة التنظيمية للمنظمة ورفع

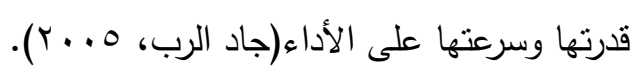

الإبداع الإداري: يثير إلى التجديد إذ يعتمد بشكل أساسي على المبادأة والمبادرة، فانطلاقا

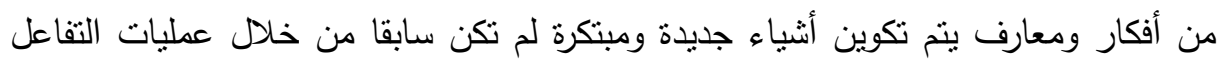

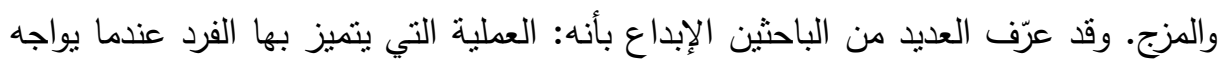

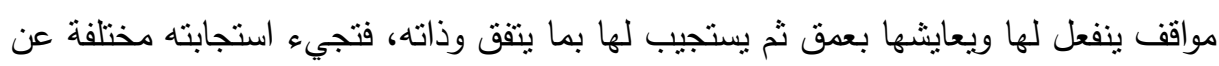

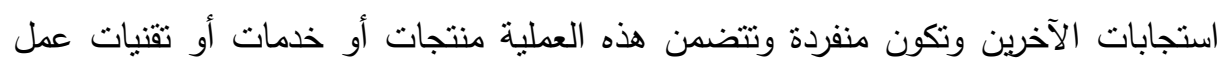

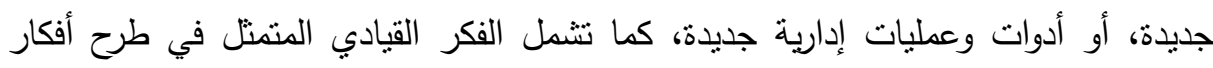

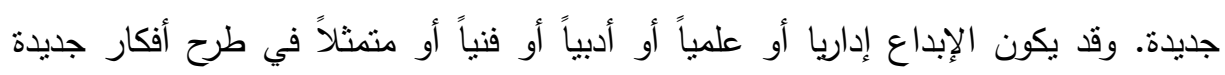

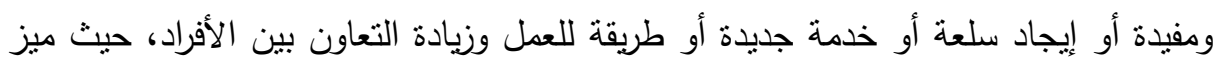

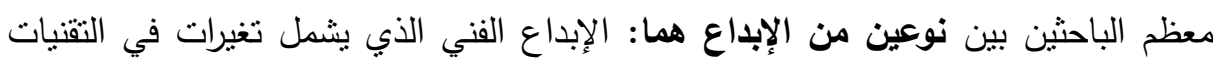

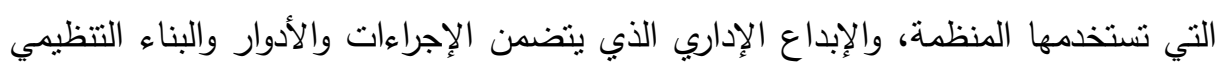

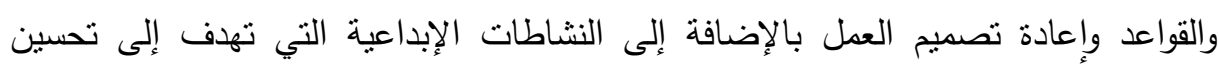

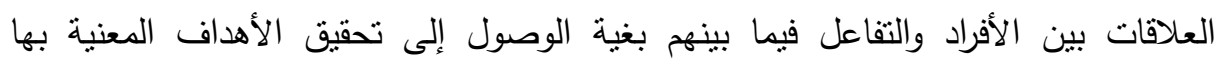

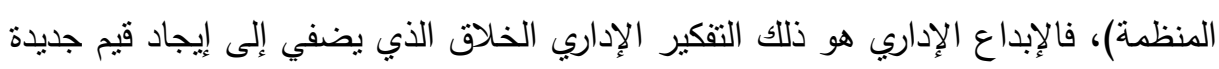

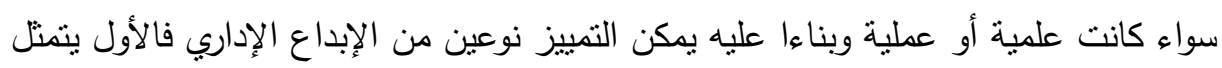

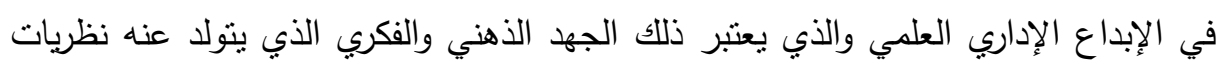

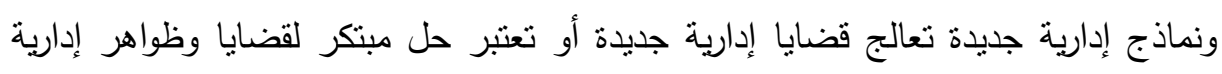

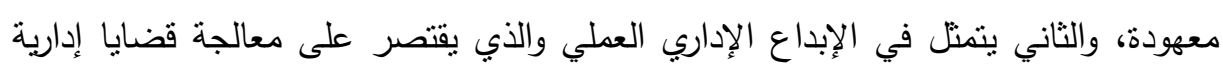
موقفية أو ظرفية، بمعنى أنه يخص المدير الذي يكون بصدد إدارة منظمته بستطيع الإبداع

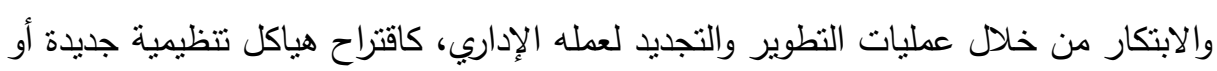

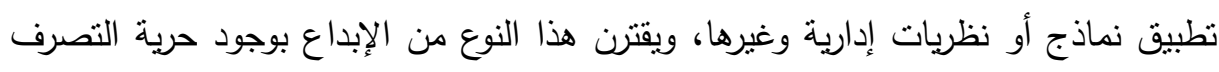

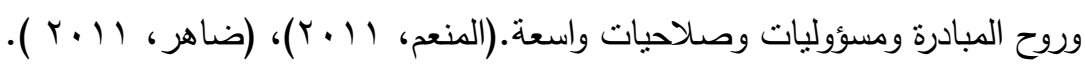




\section{منهمج الهحمث}

اعتمد الباحثون في هذه الدراسة على المزج بين المنهج الإستقرائى والمنهج الاستتباطي وذلك منخلال أسلوب الدراسة النظرية والدراسة الميدانية وذلك كمايلي:

1- الاراسة النظرية(المنهج الوصفي): في هذا الإطار اعتمدتالدراسة على المنهج الوصفي بهدف استقراء جوانب المشكلة محل الدراسة، واستعراض وتحليل نتائج الدراسات

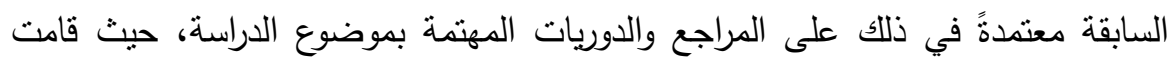

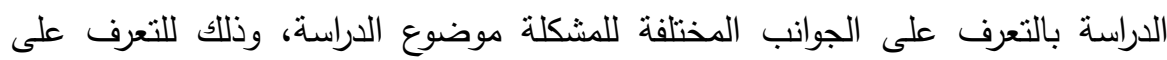

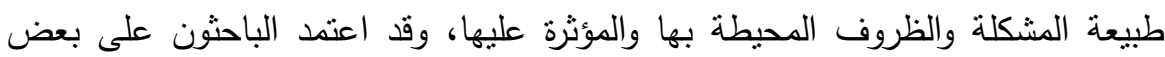
المراجع العربية والأجنبية المناحة فى هذا المجال.

r- الدراسة الميانية(المنهج التحليلي): عدد الباحثون في إجراء الدراسة الميدانية على قائمة الاستقصاء والتي تم توزيعها على عينة من المديرين والعاملين بشركات

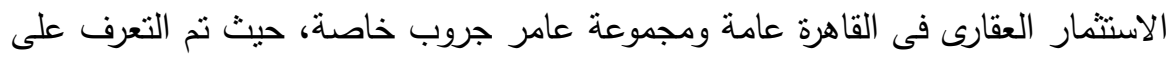
أراءهم ورغباتهم واتجاهاتهم والعناصر الغير مرضية التى تواجههم وانطباعاتهم واقتراحاتهم، وقد تم استخدام الأساليب الإحصائية في تحليل البيانات والمعطيات التي تم جمعها. مجتمع الاراسة: المديرين والعاملين بشركات الاستثمار العقارى فى القاهرة عامة ومجموعة عامر جروب خاصة عينة الدراسة: تم اختيار عينة عشوائية بسيطة من مجتمع الدراسة مكونة من بـعمفردة. أدوات الاراسة: تمثلت في استمارة الاستقصاء من اعداد الباحثون والتي تتضمنقسمين: القسم الأول: ويتعلق بالبيانات الديموجرافية للمبحوثين، (مكان العمل - الوظيفة - المؤهلمدة الخبرة في الوظيفية). 
القسم الثاني: البيانات الخاصة بمشكلة الاراسة: • الجزع الاول :بحتوى على مجموعة من العبارات متعلقة برأس المال الفكري > محور رأس المال الفكري الأول

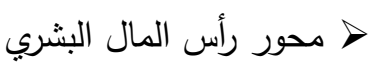

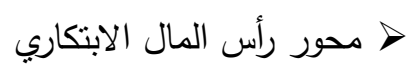

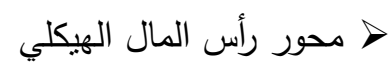
• الجزء الثاني: بحتوى على مجموعة من العبارات متعلقة بالأداء الابتكاري

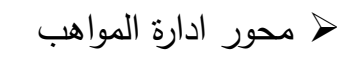
> محور التجديد والابتكار $>$ > التدريب والتعلم

> تحسينالاداء في المنظمة • الجزع الثالث: بحتوى على مجموعة من العبارات متعلقة باقتصاد المعرفة > محورالتفوق التتافسى المستدام > محور :القدرة التتافسية للؤسسات المستدامة > محور : الابتكار ( البحث و التطوير ) > محور : البنية التحتية المعلوماتية > محور :التعلم المستمر والنموالمستدام صدق وثبات الاستقصاء: قام الباحثون بإختبار قائمة الاستقصاء فى صورتها المبئية من

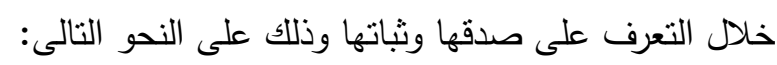

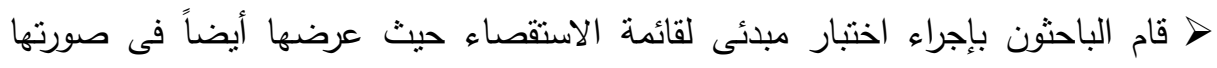

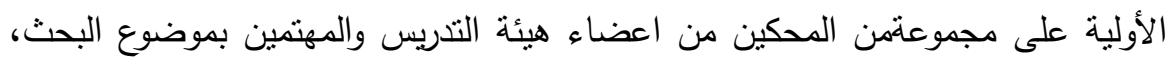
وذللك للنأكد من بساطة الصياغة ووضوح اللغة، وللتأكد أيضاً من صلاحية الاستقصاء من الناء الناحية الميدانية. 
خ نم إجراء اختبار ثنات للتأكد من إمكانية الاعتماد على نتائج البحث فى تعميم النتائج،

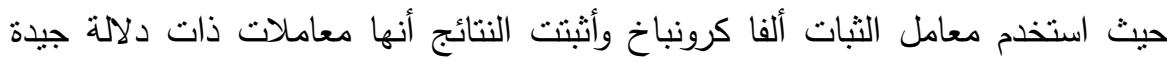

لتحقيق أهداف البحث، ويمكن الاعتماد عليها فى تعميم النتائج على مجتمع الدراسة.

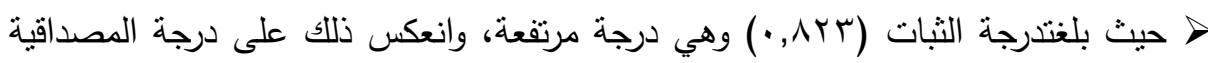

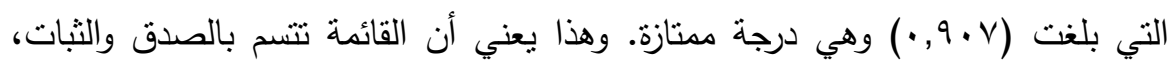
وبالتالي فإن القائمة تعتبر صالحة لجمع البيانات بما يحقق دقة البيانات الأولية المطلوبة دانة

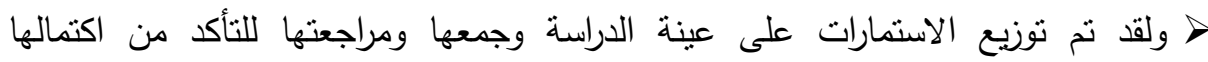
وصلاحيتها لإدخال البيانات والتحليل الإحصائي، وترميز المتغيرات والبيانات ثم تفريغها ونها

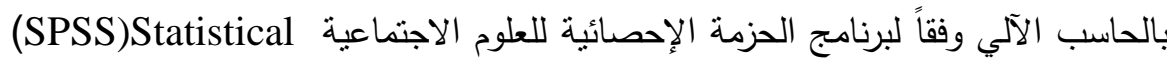

- Package for Social Sciences أساليب التحليل الإحصائي: اعتمد الباحثون على الأساليب التالية: > معامل الثبات(Alpha) كرونباخ : ويستخدم لحساب معامل الثبات، وذلك لبحث مدى إمكانية الاعتماد على نتائج الدراسة الميدانية فى تعميم النتائج. > معامل الارتباط البسيط

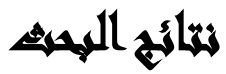

الفرض الأول: توجد علاقة جوهرية بين استثمار رأس المال الفكري وتتمية الموارد البشرية. للتحقق من صحة فرض الدراسة نم استخدام معامل الارنباط لبيرسون جدول رقم(1 ): يوضح دلالة العلاقة بين استثمار رأس المال الفكري وتتمية الموارد البشرية

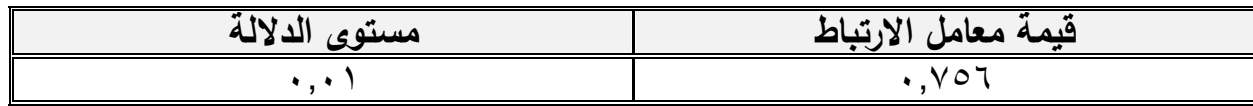

تشير بيانات الجدول السابق إلى وجود علاقة دالة إحصائيا بين استثمار رأس المال الفكري وتتمية الموارد البشرية، حيث بلغت قيمة معامل الارتباط بينهما له V0T, · عند مستوى

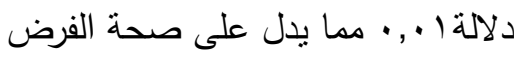


الفرض الثاني: توجد علاقة جوهرية بين استثمار رأس المال الفكري واقتصاد المعرفة . اللتحقق من صحة فرض الدراسة تم استخدام معامل الارتباط لبيرسون

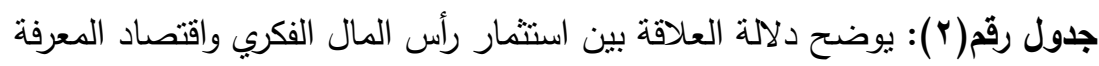

\begin{tabular}{|c|c|}
\hline مستوى الدلالة & مة معامل الارتباط \\
\hline & \\
\hline
\end{tabular}

تثتير بيانات الجدول السابق إلى وجود علاقة دالة إحصائيا بين استثمار رأس المال

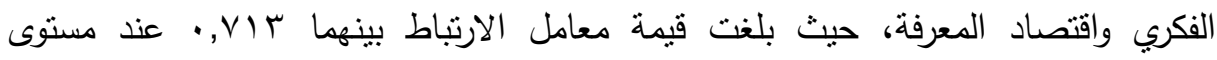

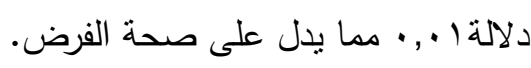

الفرض الثالث: توجد علاقة جوهرية بين تتمية الموارد البشرية واقتصاد المعرفة. للاتحقق من صحة فرض الدراسة تم استخدام معامل الارتباط لبيرسون.

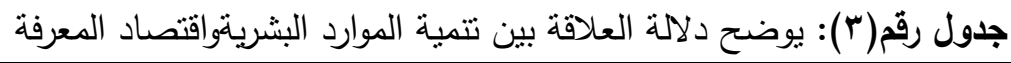

\begin{tabular}{|c|c|}
\hline مستوى الدلالة & قيمة معامل الارتباط \\
\hline $9, ., 1$ & .,AVY \\
\hline
\end{tabular}

تشير بيانات الجدول السابق إلى وجود علاقة دالة إحصائيا بين تتمية الموارد

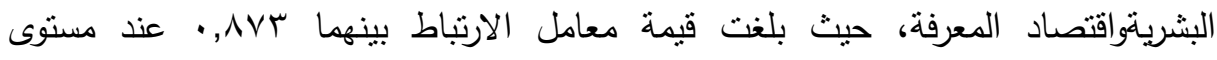

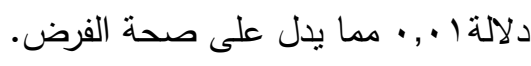
الفرض الرابع: توجد علاقة جوهرية بين استثمار رأس المال الفكري وكفاءة الأداء في

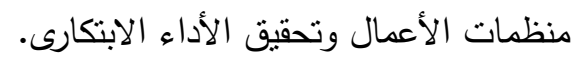
للتحقق من صحة فرض الدراسة تم استخدام معامل الارتباط لبيرسون

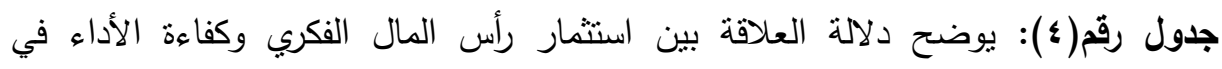
منظمات الأعمال وتحقيق الأداء الابتكارى.

\begin{tabular}{|c|c|}
\hline مستوى الالالة & قيمة معامل الارتباط \\
\hline$\cdot, ., 1$ & $\cdot, \lambda \cdot 0$ \\
\hline
\end{tabular}

تثثير بيانات الجدول السابق إلى وجود علاقة دالة إحصائيا بيناستثمار رأس المال

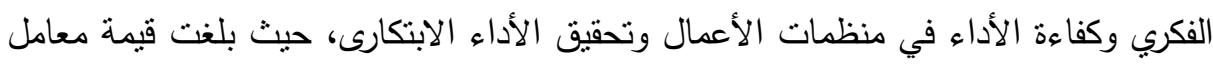

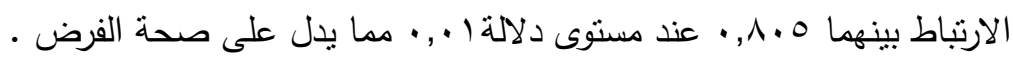

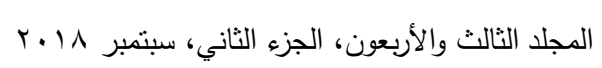




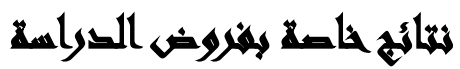

توجد علاقة جوهرية بين استثمار رأس المال الفكري وتنمية الموارد البثرية (الأداء

(الابتكاري)

> وجود علاقة ارتباطيه دالة إحصائياً عند مستوى دلالة ا.,.• بين تتمية الموارد البشرية

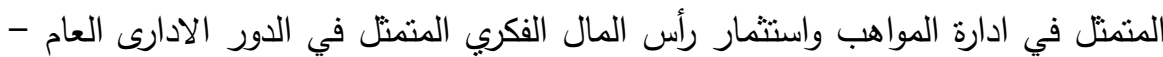

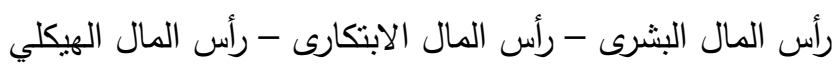

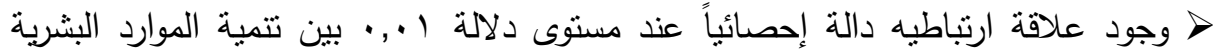

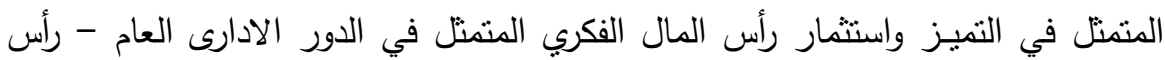

$$
\text { المال البشرى - رأس المال الابتكارى - رأس المال الهيكلي الهئ }
$$

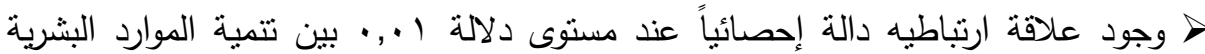

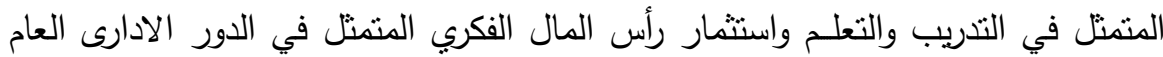

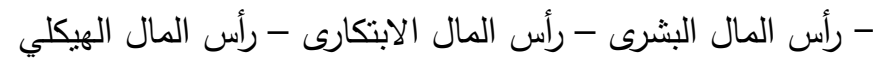

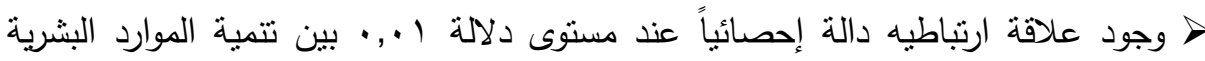

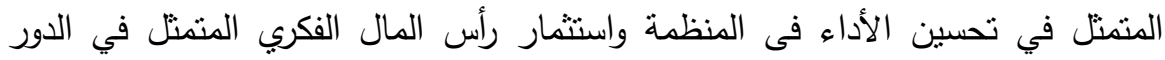
الادارى العام - رأس المال البثرى - رأس المال الابتكارى - رأس المال الهيكلي.

توجد علاقة جوهرية بين استثمار رأس المال الفكري واقتصاد المعرفة:

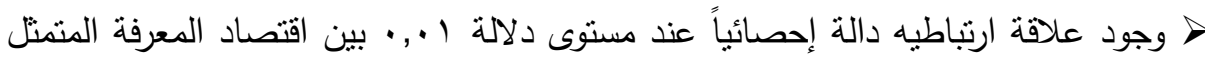

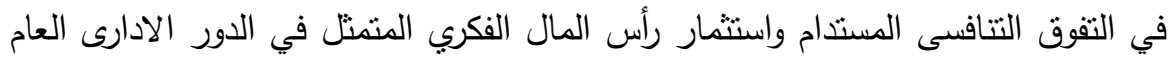

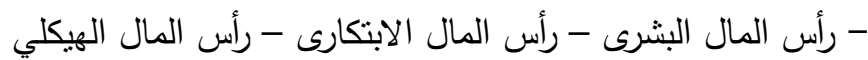

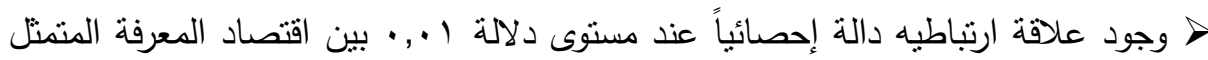

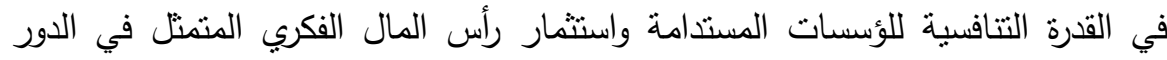

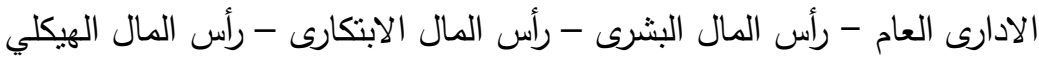

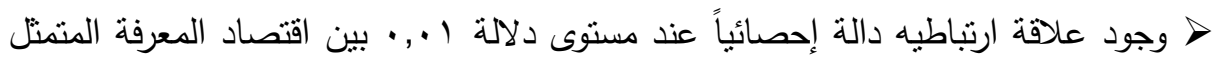

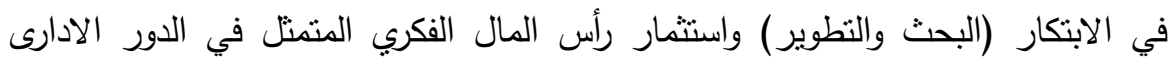




$$
\text { العام - رأس المال البشرى - رأس المال الابتكارى - رأس المال الهيكلي }
$$

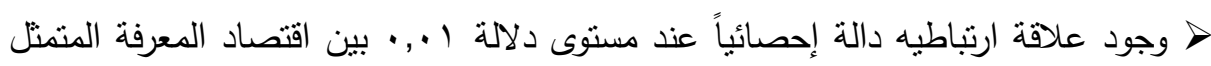

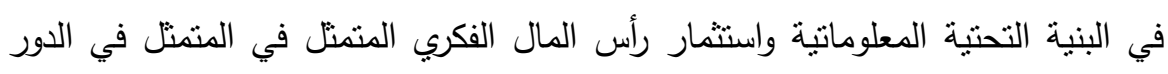

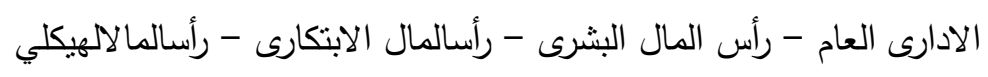

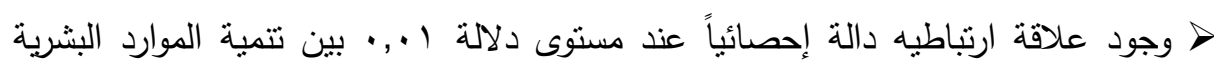

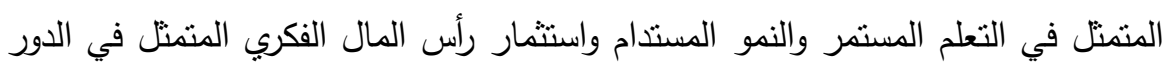

$$
\text { الادارى العام - رأس المال البشرى - رأس المال الابتكارى - رأس المال الهيكلي. }
$$

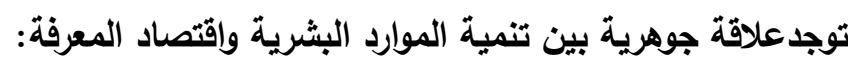

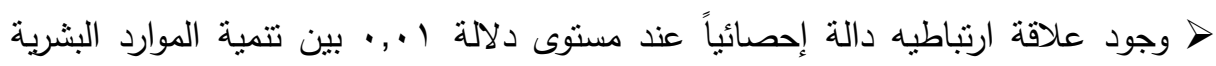
المتمنل في إدارة المواهب واقتصاد المعرفة (التفوق التتافسى المستدام- القدرة التتافسية للؤسسات المستدامة -الابتكار ( البحث والتطوير) - البنية التحتية المعلوماتية - التعلم

$$
\text { المستمر والنمو المستدام). }
$$

وجود علاقة ارتباطيه دالة إحصائياً عند مستوى دلالة ا..,. بين تتمية الموارد البشرية المتمنل في التجديد والابتكار واقتصاد المعرفة (التفوق التتافسى المستدام - القدرة التتافسية داطية للؤسسات المستدامة - الابتكار ( البحث والتطوير ) - البنية التحتية المعلوماتية - التعلم

$$
\text { المستمر والنمو المستدام). }
$$

خ وجود علاقة ارتباطيه دالة إحصائياً عند مستوى دلالة ا..,. بين تتمية الموارد البشرية

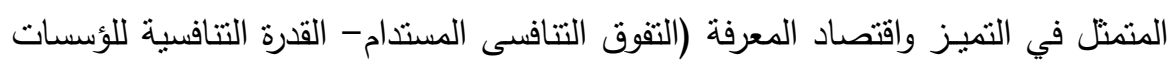

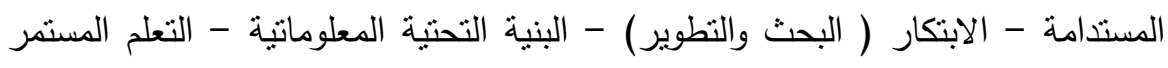

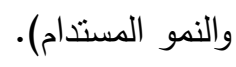

> وجود علاقة ارتباطيه دالة إحصائياً عند مستوى دلالة ا.,., بين تتمية الموارد البشرية المتمثل في التدريب والتعلـم واقتصاد المعرفة (التقوق التتافسى المستدام- القدرة التتافسية للؤسسات المستدامة - الابتكار ( البحث والتطوير ) - البنية التحتية المعلوماتية - التعلم

$$
\text { المستمر والنمو المستدام). }
$$


خ وجود علاقة ارتباطيه دالة إحصائياً عند مستوى دلالة ا +,. ب بين تتمية الموارد البشرية المتمثل في تحسين الأداء فى المنظمة واقتصاد المعرفة (التفوق التنافسى المستدام- القدرة النتافسية للؤسسات المستدامة - الابتكار ( البحث و التطوير ) - البنية التحتية المعلوماتية - التعلم المستمر والنموالمستدام).

توجد علاقة جوهرية بين استثمار رأس المال الفكري وكفاءة الأداء في منظمات الأعمال

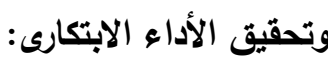

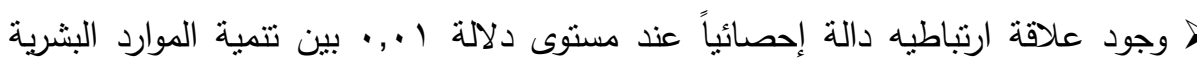

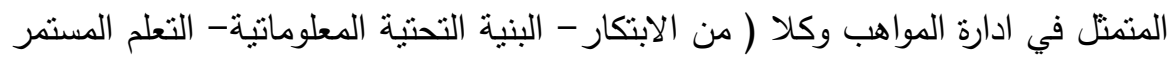
والنموالمستدام- التفوق النتافسى المستدام رأس المال البشرى- رأس المال الابنكارى)،

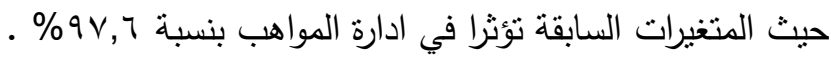

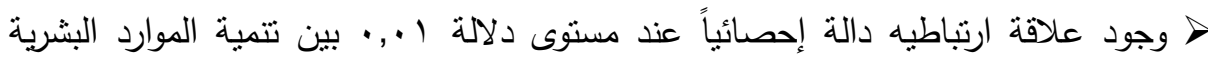
المتمثل في التجديد والابتكار والمتغيرات (الابتكار ( البحث والتطوير) - البنية التحنية

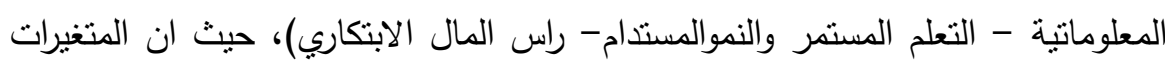

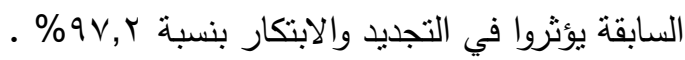

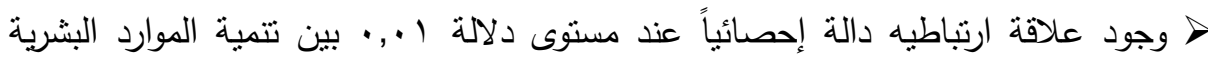

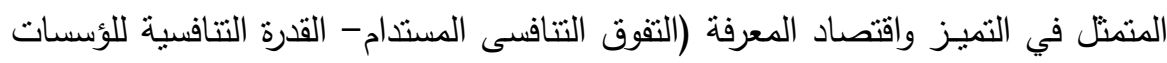

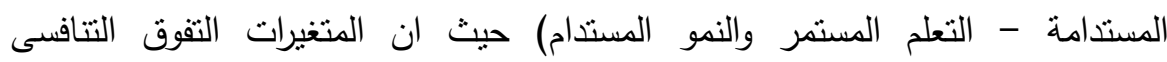
المستدام- القدرة التنافسية للؤسسات المستدامة - التعلم المستمر والنموالمستدام يؤثرا في ولئي التمييز بنسبة \%9^,؟\%. > وجود علاقة ارتباطيه دالة إحصائياً عند مستوى دلالة ا.,., بين نتمية الموارد البشرية

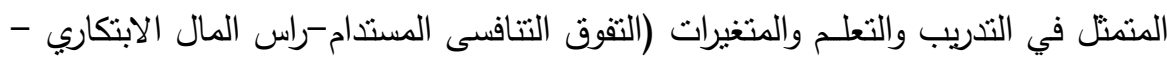

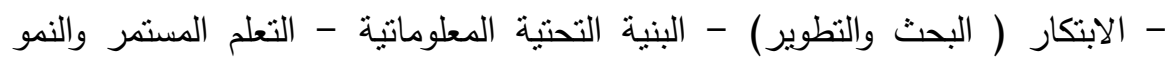

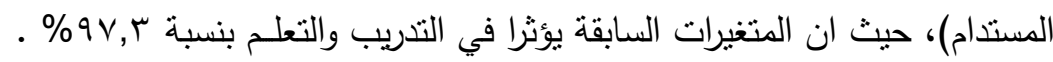


> وجود علاقة ارتباطيه دالة إحصائياً عند مستوى دلالة ا.,.• بين تتمية الموارد البشرية المتمنل في تحسين الأداء فى المنظمة واقتصاد المعرفة (التفوق التتافسى المستدام- البنية

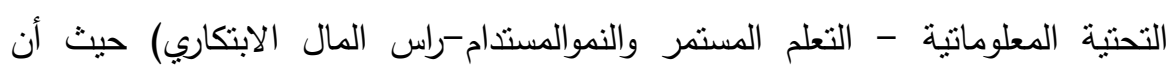

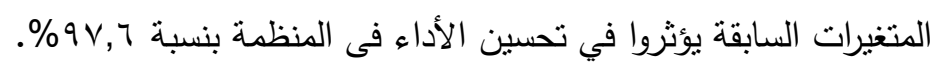

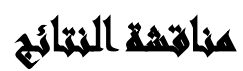

\section{النتائج الخاصة برأس المال الفكري (الدور الادارى العام):}

أثبتت الدراسة: أنتان

> أن يكون لدى الإدارة العليا فكرة واضحة عن مفهوم رأس المال الفكري لان رأس المال

$$
\text { الفكري من المداخل الحديثة التي يجب تطبيقها فى الإدارة. }
$$

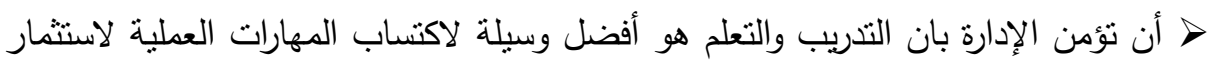

$$
\text { الموارد البشرية. }
$$

> أن يكون قيادات الإدارة مؤهلة وقادرة على أداء الأعمال الموكولة إليها بكفاءة، وان يتوافر

لدى الموظفين قدر كبير من الخبرة للتعامل مع كافة المواقف التي تتعرض لها لها الإدارة.

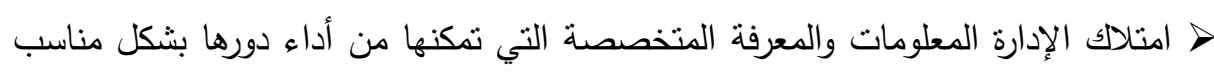

وان تقوم باستمرار بقياس درجة التحسن في أدائها.

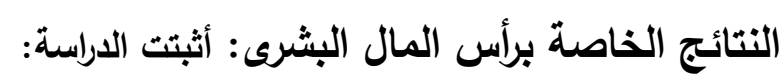

> مستوى كفاءة العاملين بالمنظمة يجب ان يكون مستوى مثاليآ ولذا يجب ان تعمل المنظمة

$$
\text { على الاحتفاظ بهم. }
$$

> إنه على قسم التخطيط فى المنظمة تقديم افكار جديدة لتطوير الخدمات وفقا لخطة زمنية.

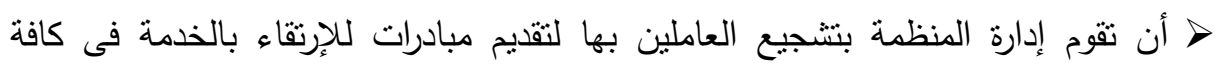

$$
\text { المستويات. }
$$

> أن المنظمة تحصل على أفضل أداء من العاملين من خلال تعاونهم فى فريق العمل لابتكار اساليب أفضل فى تقديم الخدمات للعملاء. 


\section{النتائج الخاصة برأس المال الابتكارى: أثبتت الاراسة:} > أن يكون مستوكفاءةالمديرين فى المنظمة إداء ابتكارى، وان على المنظمة الاتيان دائما بالأفكار الجديدة المبتكرة نتيجة خبرة المديرين بها، تسهل من قيام الموظفين بعملهم وتدعمه بتطوير وتحديث مهاراتهم. > أن على المنظمة بذل كل جهد لابتكار أساليب أفضل في تقديم الخدمات للعميل، وان يتميز العاملين بالمنظمة بالأداء الإبتكارى من أساليب البيع وعلى درجة لإلى عالية بالتقة

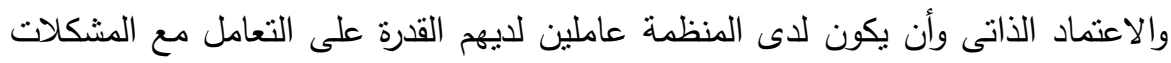

$$
\text { وحلها بالطرق الابتكارية }
$$

\section{النتائج الخاصة برأس المال الهريكلي: أثبتت الدراسة:}

> على المنظمة تتمية وتطوير الأفكار الجديدة فى كافة الادارات ماديا ومعنوياً لتحقيق الإداء

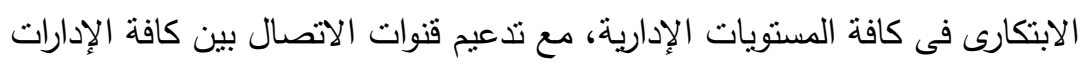
> أن يكون لدى المنظمة هيكل تتظيمي يساعد على تقارب اقسام المنظمة من بعضهور.

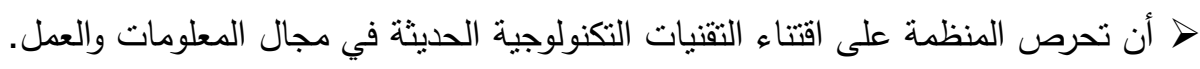
> تزود المنظمة العاملين بها بكافة التجهيزات اللازمة للعملية الاتتاجية والمساندة لاعم

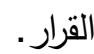

> أن يكون لدى المنظمة هيكل تتظيمى مرن غير روتينى وبيئة داعمة ومناسبة للعمل.

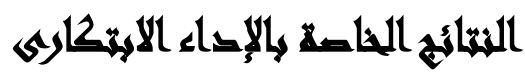

$$
\text { النتائج الخاصة بإدارة المواهب: أثبتت الدراسة: }
$$

> أن تمنلك المنظمة توجيهات محددة وواضحة لجذب الموهوبين في الادارات العليا والادارات

> أن تخصص المنظمة ميزانية خاصة لجذب المديرين الموهوبين وتوظيفهم.

> أن تتيح المنظمة الفرصة للعاملين الموهوبين لاتخاذ القرارات التي تؤثر على عملهم.

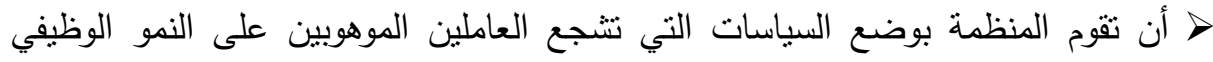


وتوفير فرص الالتحاق بالمناصب العليا.

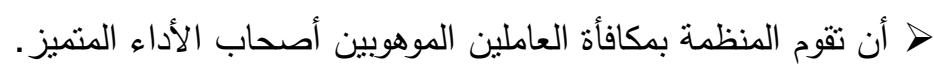
> أن تعمل المنظمة على توفير بيئة عمل تجعل العاملين الموهوبين متحمسين للأداء اعمالهم بشكل إبتكارى.

النتائج الخاصة بإلتجديد والابتكار : أثبتت الدراسة: > على المنظمة ان يكون لديها القدرة على تقديم أفكار جديدة تسهم في تطوير الأداء والعمل. > أن تتبنى الإدارة سياسة معلنة لنتجيع الابتكار والتجديد. > أن توفر الإدارة بيئة عمل تشجع على الابتكار والتجديد. > أن يكون لدى المنظمة مدراء يتميزوا بالإبداع و الابتكار في أدائهم.

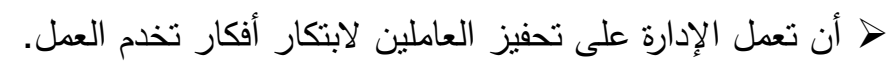
النتائج الخاصة بالتمبيز: أثبتت الاراسة: > أن يكون لدى الموظفين المام ومعرفة بطبيعة الأعمال الموكلة إليهم لتدفعهم للتمييز .

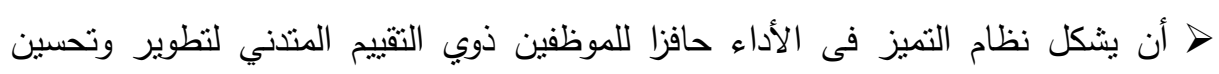
أدائهم الوظيفي. > أن تعمل إدارة المنظمة باستمرار من أجل تحديث وتطوير نظام تقييم الأداء السنوي ليسهم

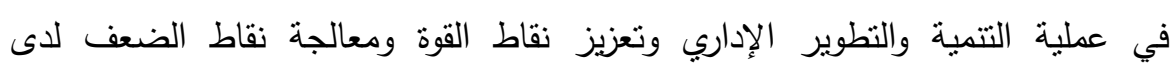
العاملين. > أن نسعى إدارة المنظمة لتبنى الأساليب الجديدة للعمل بها داخل المنظمة لاكتساب مهارات

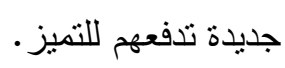
> أن يكون لدى إدارة المنظمة توجه واضح من أجل الحصول على جوائز الجودة والتمييز . > أن تكون بيئة العمل بالمنظمة محفزة ومشجعة للإبداع والابتكاروالتميز . النتائج الخاصة بالتدريب والتعلم: أثبتت الدراسة:

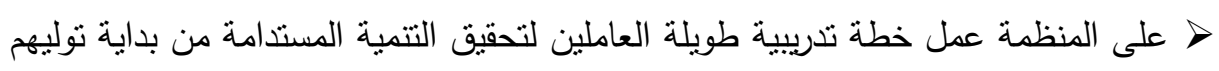
المسئولية.

> أن تقوم المنظمة بتحديد الاحتباجات التدريبية على مستوي كل قسم وكل إدارة.

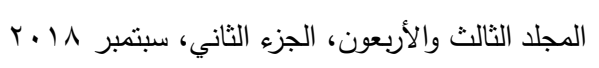




$$
\text { أن يكون لاى المنظمة ميزانية خاصة للتنريب والتعلم. }
$$

> أن تقوم الإدارة بمساعدة العاملين الجدد في تتمية مهاراتهم وقدراتهم وتساعدهم على مئى

$$
\text { التوجيه والأشراف والتدريب. }
$$

أن تتيح إدارة المنظمة خدمات وبرامج غير موجودة عند غيرها من المنظمات.

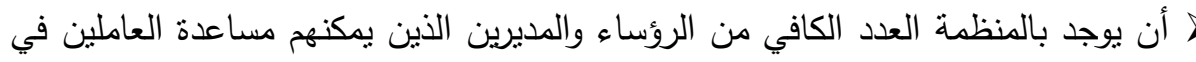
عملية التعلم والتطوير •

\section{النتائج الخاصة بالتحسين الأداء فى المنظمة: أثبتت الاراسة:}

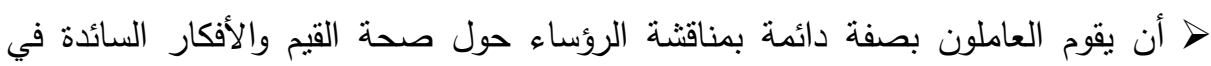
المنظمة لتحسين الأداء.

> أن يكون لدى المنظمة استراتجيات جديدة لايمكن التتبؤ بها بناء على أعمالها السابقة ومؤشرات الأداء بالمنظمة.

> أنيكون لدى المنظمة نظام إدارى منظور يسعى الى تحقيق الاداء الابنكارى فى المنظمة.

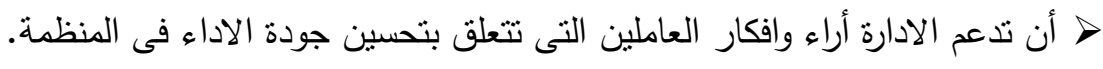

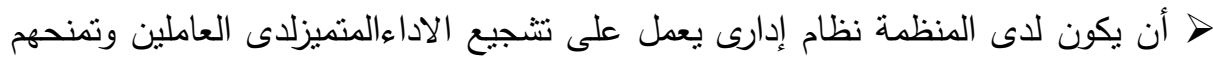
المكأفات للاستمرار فى تحسين إدائهم. > أن تقوم المنظمة بإجراء التغييرات على المستوى الاسترتيجى استجابة لما يحصل من إنهاء أخطاء معها ومع المنافسين لتحسين ادائها.

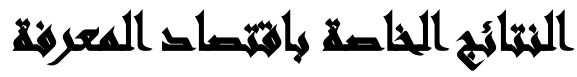

النتائج الخاصة بالتقوق التنافسى المستدام: أثبتت الاراسة: > أن التفوق التنافسي يتحقق بالاسبقية فى التكلفة والجودة والمرونة والتسليم والابداع > أن تعمل المنظمة على خلق فرص جديدة لتخفيض تكاليفها الكلية وزيادة الربحية والنمو .

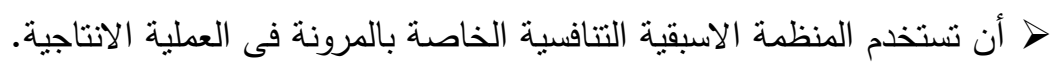

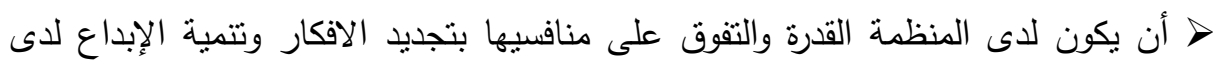


العاملين.

> أن نركز المنظمة على الجودة الثاملة من خلال استخدام إستراتيجية التفوق التتافسى

$$
\text { المستدام. }
$$

> للتسليم دور هام فى نجاح إستراتيجية التفوق التتافسى لدى المنظمة.

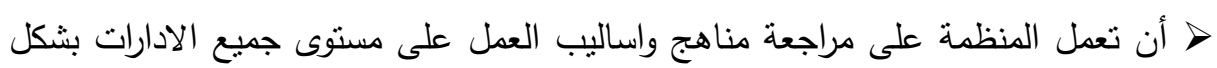
منتظم ومستمر لضمان تحقيق التفوق التتافسى.

النتائج الخاصة بالتنافسية للمؤسسات المستدامة: أثبتث الدراسة: > أن يكون لاى المنظمة القدرة النتافسية على التكييف مع أى تغيرات ومتطلبات جديدة

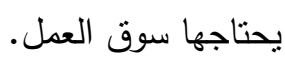

> أن تقوم المنظمة بدراسة تطور اداء الثركات المنافسة العاملة فى نفس مجالها.

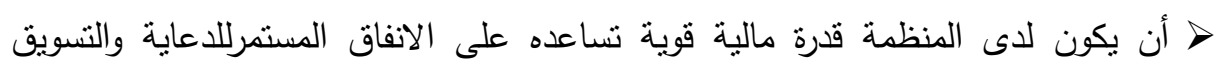
للحفاظ على تواجدها.

> أن يكون لدى المنظمة إدارة تقوم على تقييم أسعارها بالمقارنة بالشركات المنافسة.

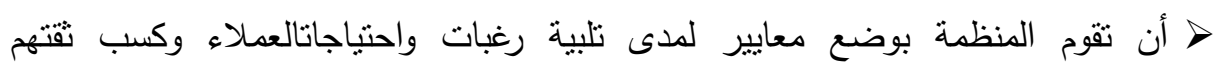
لاستمرارها بقدرة تتافسية عالية. > أن يكون لدى المنظمة القدرة على اكتثاف أوجه القصور والضعف فئ الثركات المنافسة والاستفادة منها.

النتائج الخاصة بالابتكار البحث والتطور: أثبتت الاراسة أن لتحقى الابتكار والبحث والتطور فيجب تميز المنظمة بالآتي: > أن يكون لدى المنظمة ميزانية مخصصة لتعزيزالمعرفة ودعم الابتكار والبحث والتطوير

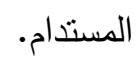

> أن تتواجد تكنولوجية إبتكارية جديدة قائمة على أستدامة العلم والتكنولوجيا .

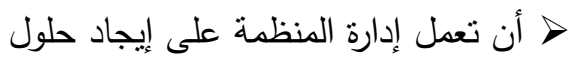
> أن تعمل المنظمة على تعزيز تكنولوجيا المعلومات والاتصالات الجديدة المبتكرة. > أن تقوم المنظمة بتحفيز الاستخدام الفعال للمعرفة الجديدة والمبتكرة.

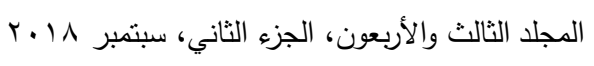


> أن تقوم المنظمة بأستخدام أفضل الامكانيات الجديدة لتوزيع ونشر المعلومات. > أن يكون لاى المنظمة احدث الوسائل التسويقية المبتكرة للوصول الى العميل المستهدف.

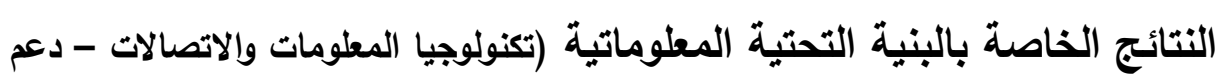
النشاط الاقتصادى ). أثبتت الاراسة: أن لتحقق البنية التحتية المعلوماتية فعلى المنظمة أن تقوم بالآتي: > أن تقوم المنظمة بمعالجة الموارد المعلوماتية ونشرها داخل حدود الثبكة التنظيمية

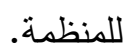
> أن يكون لاى المنظمة برامج وتطبيقات حديثة تساهم فى زيادة قدرة العاملين على الابتكار والمنافسة. > أن تعمل تكنولوجيا المعلومات على توفير الوقت والجهد للعاملين واتاحة الفرصة لهم

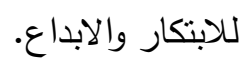

> أن تتيح المنظمة استخدام الانترنت لكافة العاملين بما يدعم تبادلهم لمزيد من المعرفة والمعلومات لتتمية مهاراتهم. > أن تعمل المنظمة على نظام ربط الحوافز بمدى الابتكار والابداع فى أداء الاعمال.

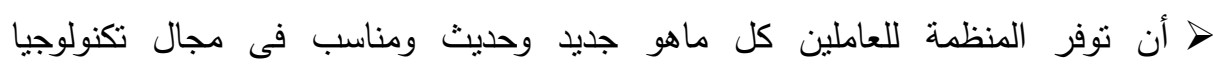
المعلومات.

النتائج الخاصة بالتعلم المستمر والنمو المستدام (الايدى العاملة الماهرة والابداعية- رأس المال البشرى القادر على دمج التكنولوجيا فى العمل). أثبتت الدراسة: أن لتحقق التعلم المستمر والنموالمستدام فعلى المنظمة أن تقوم بالآتي:

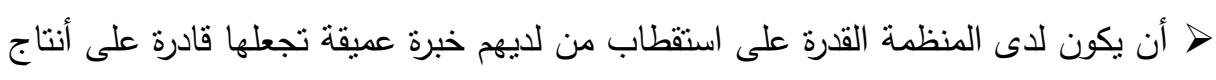
الموارد المعرفية ونشرها فى ما بينها. > أن توفر الادارة العليا الامكانيات المطلوبة لتتمية القدرات الابداعية والابتكارية للعاملين.

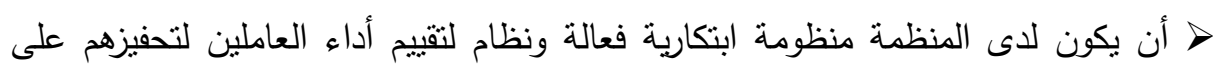

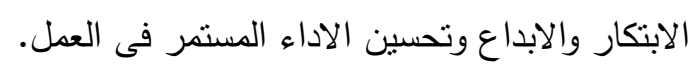


> أن تعمل الأدارة على توفير دورات تدريبية للعاملين لزيادة مهاراتهم وتحسين أدائهم

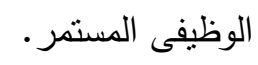

> أن تعمل المنظمة على تمكين العاملين وتقويضهم فى الكثير من السلطات لحثهم على العى

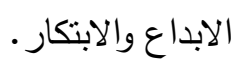

> أن يكون لاى المنظمة مناخ بيئى مناسب ومحفز لافراز الافكار الجديدة المبنكرة والتعلم

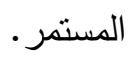

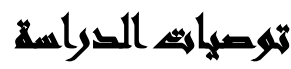

$$
\text { > خ ضرورة التوصيات والمقترحات حسب نتائج هذه الدراسة: }
$$

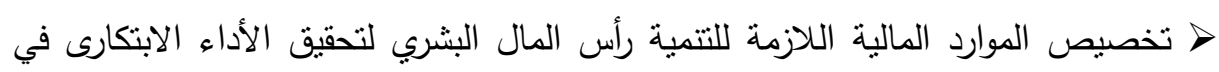
ظل اقتصاد المعرفة > استخدام مؤشرات أداء واضحة لمراقبة تتفيذ الخطة الاستراتيجية لتتمية الموارد البشرية وتحسين رأس المال الفكري لتحقيق الأداء الابتكارى في ظل القتصاد المعرفة.

\section{المرالم:}

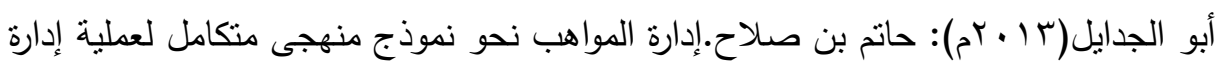

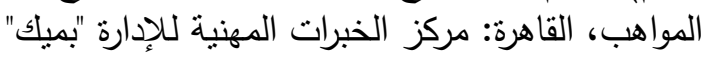

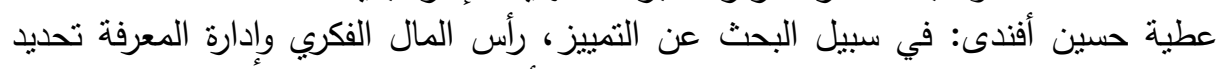

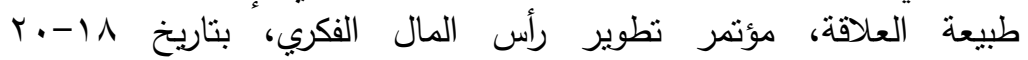

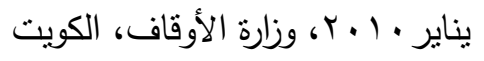

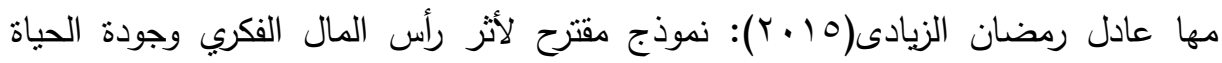

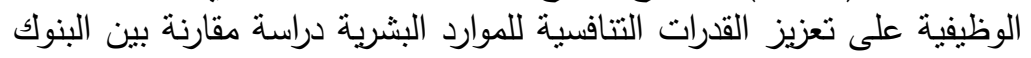

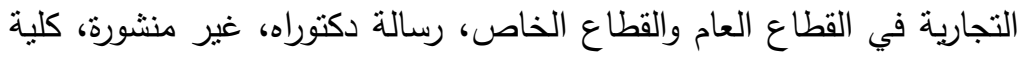
التجارة، جامعة عين شمس في التعار 
بلوناس، عبد اله وأمينة، قدايفة: دور رأس المال الفكري في تحقيق الميزة النتافسية لمنظمات

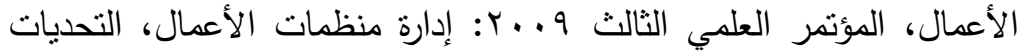

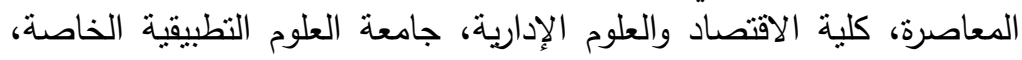

$$
\text { الأردن }
$$

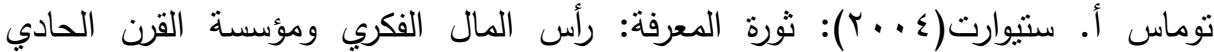

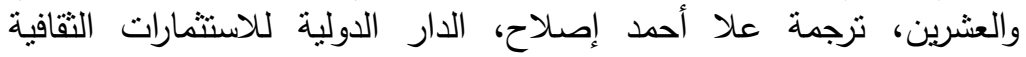

عيسى دراجى: الاستثمار في رأس المال الفكري، الملتقى الدولي الخامس حول رأس المال

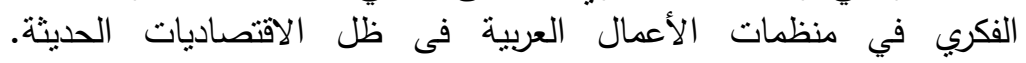

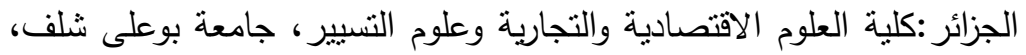

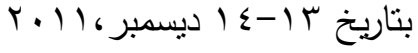

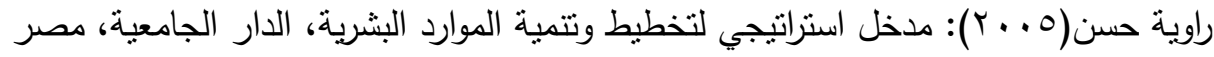

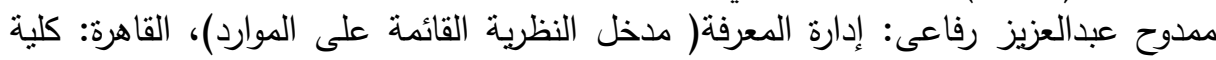

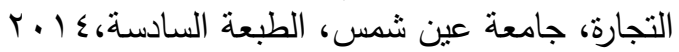

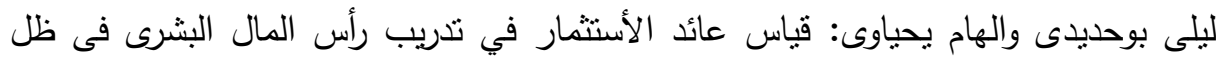

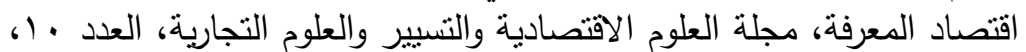

$$
r \cdot 1 r
$$

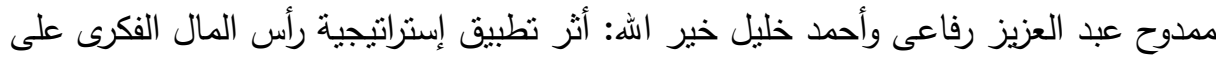

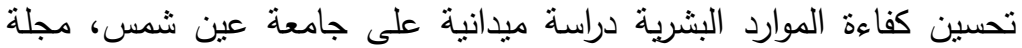

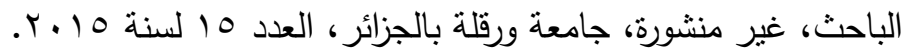

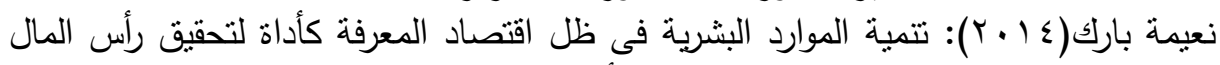

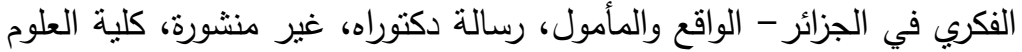
الاقتصادية، العلوم التجارية وعلوم التسيير، والترالية جامعة محمد الثريف مساعدية،

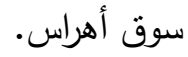

هدى سليمان محمود(10 • ب): أثر الرعاية المهنية على تتمية الموارد البشرية لتحقيق التتمية

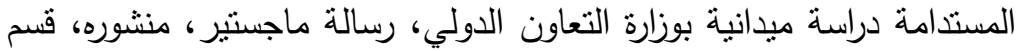

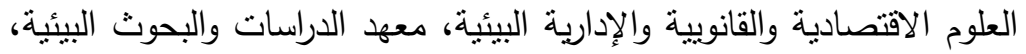

$$
\text { جامعة عين شمس الإن }
$$

Schiavone, Francesco(2014): Meles, Antonio; Verdoliva, Vincenzo; \& Del Giudice, Manlio Does location in a science park really matter for firms' intellectual capital performance?, Journal of Intellectual Capital. Vol. 15, No. 4, pp. 497-515..

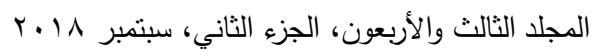


Khalique, Muhammad; Bontis, Nick; Bin Shaari, Jamal Abdul Nassir; \& Muhammad Isa, Abu Hassan (2015): Intellectual capital in small and medium enterprises in Pakistan, Journal of Intellectual Capital. Vol.16, No.1, pp.224-238.

\title{
THE INVESTMENT IN THE INTELLECTUAL \\ CAPITAL FOR ACHIEVING INNOVATIVE PERFORMANCE IN TERMS OF ECONOMY OF COGNITION
}

Gad, Mahasen, A. N. M. ${ }^{(1)}$; Mandour, A. F. ${ }^{(2)}$ and El-Shahat, Nehal, F. ${ }^{(1)}$

1) Institute of Environmental Studies \& Research, Ain Shams University 2) Faculty of Commerce, Ain Shams University

\begin{abstract}
Egypt considers one of the richest states of the world owning human wealth; but unfortunately, has no unique position in development of this field (development of human capital). Hereby, the need for treatment of this problem Egypt meets in growth and development in general and in investment of intellectual capital reflected in human capital in particular is needed. Since the intellectual capital is a collection of experiences, knowledge, energies, and innovated and creative properties individuals have and invest at work for the purpose of achieving sustainable development at an organization which is also a reason for progress, growth and development of the world states. Hereby, investment in intellectual capital will be examined as an approach for developing human resources and achieving innovative performance of the human element's sustainability in terms of economy of cognition. Researchers use the descriptive-analytical method and appropriate statistical tests for testing validity of hypotheses and answering the study questions. Given the sample

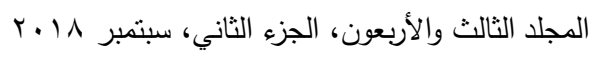


مجلة العلوم البيئية

معهد الدراسات والبحوث البيئية - جامعة عين شمس

consisting of (285) forms, researchers come to several results and recommendations which most important is that there is a relationship among investment of intellectual capital, efficiency of performance in business organization, and fulfilling innovative performance. Consequently, development of human resources should be considered through investing the intellectual capital and economy of cognition. 